\title{
Have We Finally Achieved Actuarial Fairness of Social Security Retirement Benefits and Will It Last?
}

\author{
Frank W. Heiland and $\mathrm{Na}$ Yin
}

Project \#: UM13-02 


\title{
Have We Finally Achieved Actuarial Fairness of Social Security Retirement Benefits and Will It Last?
}

\author{
Frank W. Heiland \\ City University of New York, Baruch College \\ Na Yin \\ City University of New York, Baruch College \\ April 2014 \\ Michigan Retirement Research Center \\ University of Michigan \\ P.O. Box 1248 \\ Ann Arbor, MI 48104 \\ www.mrrc.isr.umich.edu \\ (734) 615-0422
}

\section{Acknowledgements}

This work was supported by a grant from the Social Security Administration through the Michigan Retirement Research Center (Grant \# 5 RRC08098401-05-00). The findings and conclusions expressed are solely those of the author and do not represent the views of the Social Security Administration, any agency of the Federal government, or the Michigan Retirement Research Center. 


\title{
Have We Finally Achieved Actuarial Fairness of Social Security Retirement Benefits and Will It Last?
}

\begin{abstract}
This paper develops a framework to analyze the actuarial adjustments faced by American workers who claim Social Security benefits before or after their Full Retirement Age (FRA). We derive the conditions under which these adjustments are "actuarially fair" (or "neutral”) and develop measures to characterize the devi- ation from the fair form. Fair adjustment schedules are increasing at an increasing rate in take-up age and become flatter as longevity rises. We document that the actuarial fit has improved across generations. Our baseline 3\% discount rate scenario estimates that the current schedule deviates from its fair form by less than $1 \%$ for average-mortality beneficiaries, compared to $5.1 \%$ and $4.0 \%$ for male and female beneficiaries in 1980, respectively. The improvement is largely due to the increases in the Delayed Retirement Credit. For men, gains in life expectancy combined with the increase in the FRA also contributed to the improved fit. We predict that the designated increase in the FRA to age 67 will have little effect on the actuarial fit. We investi- gate schedules reflecting (further) increases in the retirement ages, as recommended by the President's 2010 Fiscal Commission, and propose alternatives. We also discuss results from the analysis of the adjustments to spousal and widow(er) benefits.
\end{abstract}

\section{Citation}

Heiland, Frank W. and Na Yin (2014). "Have We Finally Achieved Actuarial Fairness of Social Security Retirement Benefits and Will It Last?” Ann Arbor MI: University of Michigan Retirement Research Center (MRRC) Working Paper, WP 2014-307. http://www.mrrc.isr.umich.edu/publications/papers/pdf/wp307.pdf

\section{Authors’ Acknowledgements}

We are grateful to Cordelia Reimers, Hugo Benítez-Silva, Sanders Korenman, Tony Webb, and Courtney Coile for helpful comments and discussion. Andrew Silverstein, Edouard Chrétien, and Mini Kyung provided excellent research assistance. We acknowledge financial support from the Social Security Administration through the Michigan Retirement Research Center Grant 3002516538UM13-02. 


\section{Introduction}

The U.S. Social Security system is one of the largest and most comprehensive social insurance programs worldwide. In 2010, 90\% of individuals age 60-64 were fully insured and $\$ 577.4$ billion were paid in old-age retirement and survivor's benefits (SSA-S, 2010, Table 4.C5). Social Security reduces, by a constant percentage, the monthly benefits of workers who start collecting checks before the Full Retirement Age (FRA), as early as age 62, the Early Retirement Age (ERA). Likewise, it increases benefits for those who delay take-up past $F R A$ in accordance with the Delayed Retirement Credit (DRC).

Since the introduction of the early retirement option in 1956 (1961) for women (men), the structure of the actuarial adjustments (henceforth: "the adjustment schedule") has been modified several times. As shown in Table 1 and Figure 1, the DRCs have been raised from 3\% to 8\% per year, which has increased the slope of the schedule after FRA. Following the 1983 Social Security Amendments, the $F R A$ has increased from age 65 to 66 , resulting in a wider early take-up age range $(E R A-F R A)$ relative to delayed take-up $(F R A-70)$, and a lower penalty rate three years prior to $F R A$ was introduced. The $F R A$ is scheduled to rise to 67 for beneficiaries reaching ERA by 2022. ${ }^{1}$ Current policy proposals, such as the recommendations made by President Obama's 2010 Fiscal Commission, call for increases in the ERA and the FRA to age 64 and 69, respectively. Such reforms, if implemented, would lead to important changes in the adjustment schedule that may fundamentally alter the incentives for benefit take-up faced by future generations of beneficiaries.

These adjustments are a key feature of the program, affecting the monthly checks of millions of current and future beneficiaries. ${ }^{2}$ They provide incentives that are fundamental to retirement planning. ${ }^{3}$ How benefits are adjusted also impacts the finances of the program, since the adjustment scheduletogether with the beneficiaries' lifespans and take-up behavior-determines Social Security's outlays. ${ }^{4}$

\footnotetext{
${ }^{1}$ For a comprehensive treatment of the history of Social Security legislation see Myers (1993).

${ }^{2}$ Myers and Schobel (1990), Gustman and Steinmeier (1991), Myers (1993, p.52), Gruber and Orszag (2003), and Benítez-Silva and Heiland (2007, 2008), among others, discuss the rules in detail.

${ }^{3}$ The retirement literature routinely models the benefit adjustments as part of the trade-offs that determine labor supply and claiming behavior (e.g., van der Klaauw and Wolpin, 2008; Coile and Gruber, 2007; Benítez-Silva and Heiland, 2007; French, 2005; Gustman and Steinmeier, 2002; Rust and Phelan, 1997).

${ }^{4}$ Most beneficiaries claim before reaching FRA, with around 50\% of retirees taking up benefits between age 62 and 63 (e.g., Benítez-Silva and Yin, 2009).
} 
Suppose, for example, that there were no penalty for claiming benefits at the ERA instead of the FRA. Social Security's outlays would increase by up to $F R A-E R A$ years' worth of benefits per person (in present value terms). Setting an adjustment policy that makes outlays independent of take-up behavior for average-mortality beneficiaries will likely reduce outlay volatility. Hence, from a systemic perspective, it may be desirable to implement adjustments that are "actuarially fair" (or "neutral") to Social Security, such that the expected discounted present value of lifetime benefit payouts do not vary by age at take-up, on average (see Burkhauser, 1980; Myers and Schobel, 1990; Gruber and Wise, 2005). ${ }^{5}$

Demographic trends present an important backdrop to understanding changes in the adjustment policies. The 1983 Social Security Amendments, which led to the increase in the FRA to age 66 today, were motivated in part by the rapid increases in old-age longevity. Average remaining life expectancy at age $62(E R A)$ increased from 16.5 (21.3) years to $19.6(22.7)$ years for males (females) born in 1918 compared to 1937.6 As average retirement lifespans lengthen, adjustment schedules that were actuarially fair for average beneficiaries from past generations may not be fair for current retirees. On the other hand, an adjustment policy that was far from actuarially fair may be more congruous now.

This motivates the questions that we seek to address in this paper: Under what conditions are the adjustments to benefits for early and delayed take-up actuarially fair? To what degree have past policy changes improved the actuarial fairness of the adjustment schedule for average mortality males and females? How will the planned adjustment schedules perform for future beneficiaries under different demographic scenarios and are there superior adjustment policies that should also be considered?

While we are not aware of any recent analysis by researchers at Social Security, Robert Myers, the chief actuary of Social Security from 1947 to 1970, and his co-author, argued in a 1990 paper that the penalties for early take-up associated with FRA 65 are "reasonably close to the theoretically correct values" (the actuarially fair ones) for beneficiaries retiring in 1990 and 2030 (see Myers and Schobel, 1990, p.295). ${ }^{7}$ The $D R C$ has been described as too small to be actuarially fair before reaching $8 \%$ per

\footnotetext{
${ }^{5}$ Some authors use alternative terminology to describe the same concept. Queisser and Whitehouse (2006) use the term actuarial neutrality, Duggan and Soares (2002) use actuarial equivalence, and Crawford and Lilien (1981) refer to marginal fairness. We note that the pension literature sometimes uses the term actuarial fairness when comparing benefits and contributions (e.g., Queisser and Whitehouse, 2006; Belloni and Maccheroni, 2006).

${ }^{6}$ The values are obtained from logistic mortality trend models estimated using data from birth cohorts 1900-1948.

${ }^{7}$ The retirement literature frequently refers to the early take-up penalties as (approximately) actuarially fair for average
} 
year (Myers and Schobel, 1990; Duggan and Soares, 2002; Queisser and Whitehouse, 2006).

Systematic evidence on the actuarial properties of the adjustment schedules is lacking. ${ }^{8}$ Notable exceptions are the studies by Duggan and Soares (2002), Queisser and Whitehouse (2006), and Shoven and Slavov (2014). Duggan and Soares examine the actuarial fairness across gender and earnings groups among actual beneficiaries born in 1917-1933, cohorts that all faced the same penalties for early take-up (FRA 65 schedule) but different $D R C$ s ranging from $3 \%$ to 5.5\%. Comparing actual and actuarially fair benefits, they find that men who claimed early (especially those with low earnings) enjoyed an actuarial premium. Women who claimed early, on the other hand, faced less than actuarially fair benefits, owing to their longer lifespans. Queisser and Whitehouse compare the actuarial fairness of the average annual reductions for early and delayed benefit take-up across OECD countries. Their main result pertaining to the U.S. is for the future adjustment schedule $F R A 67$. The fair average reduction for early take-up is estimated to be $8.2 \%$ per year, exceeding the actual penalty by 2.2 percentage points.

Shoven and Slavov (2014) calculate the actuarial (dis)advantage of delaying receipts of Social Security benefits from age 62 to later ages (up to age 70) for individuals who reside in different types of households (single, one-earner couple, and two-earner couple) and whose mortality differs from the average. They are mainly interested in the optimal take-up ages for different types of households and focus on the 1951 birth cohort (and the 1953 birth cohort for the second earner of the couple), which is the most recent cohort reaching eligibility age. In their baseline case, they find that delay is actuarially advantageous for a large fraction of households. Contrasting these results to individuals born in 1900, they report a significant increase in the gains from delayed take-up.

Previous research has focused on selected adjustment policies and generations. The present study has a more comprehensive scope as it examines the implications of the changes in the adjustment policy across beneficiaries born between 1917 and 1960, drawing careful distinctions between the contribution mortality Americans. For example, Gruber and Wise (2005, p.6, Footnote 2) write: Under current law, benefits in the United States are actuarially fair between 62 and 65, but are increased less than actuarially if the receipt of benefits is delayed beyond age 65, thus providing an incentive to leave the labor force at 65. Benefits will eventually become actuarially fair after age 65 as well. Similar statements can be found elsewhere (e.g., Crawford and Lilien, 1981, p.515; Benítez-Silva and Heiland, 2007, p.531; and Sun and Webb, 2009, p.3).

${ }^{8}$ The paper by Myers and Schobel (1990) mentioned above is one of a handful of earlier, more qualitative studies that focus on at most two cohorts (Blinder et al., 1980; Mirer, 1998; Liu and Rettenmaier, 2006). 
of the early take-up penalty structure, the $D R C$, and the $F R A$, as well as (average) cohort mortality. We provide a detailed analysis of the conditions under which adjustments are actuarially fair and develop measures to quantify the extent and nature of the deviation from the fair form. The tools and procedures developed here can be applied to any adjustment schedule and demographic.

We show that fair adjustment schedules increase at an increasing rate in the take-up age and should be flatter when mortality is lower. We demonstrate that the fit of the adjustments to worker benefits has improved notably. We predict that the designated increase in the FRA from age 66 to age 67 will not significantly alter the actuarial fit, even if life expectancy continues to increase. We investigate the impact of further increases in retirement ages, as recommended by the President's 2010 Fiscal Commission, and evaluate alternative schedules that better adhere to the curvature required by actuarial fairness. We also briefly discuss results from the analysis of spousal and widow(er) benefits.

\section{Rules of Benefit Take-up and Adjustment}

\subsection{Benefit calculation}

Individuals aged 62 or older who have paid Social Security payroll tax for at least 10 years (if born in 1929 or later) are eligible for retirement benefits under the Social Security Old-Age (SSOA) benefits

program. The system is financed by a tax on earnings up to a maximum. To determine the Monthly Benefit Amount $(M B A)$, the Social Security Administration calculates the Primary Insurance Amount (PIA) of a worker as a function of the worker's average earnings subject to Social Security taxes taken over her 35 years of highest earnings. Since 1972, the PIA has been indexed to the Consumer Price Level (CPI) after age 60.

\subsection{Early and delayed take-up}

The penalties and credits for early and delayed take-up are given as percentage adjustments in benefit levels relative to take-up at $F R A$. The earlier (later) benefits are claimed relative to $F R A$, the greater 
the cumulative penalty (credit) to benefits. Formally, we denote the adjustment to full benefits for early or delayed take-up by $r(a)$. For take-up before $F R A, r(a)$ will be negative as benefits are reduced. ${ }^{9}$ If benefits are claimed at FRA, the $M B A$ equals the PIA. If a worker starts receiving benefits before the $F R A$ and retires from the workforce or stays below the earnings limits prescribed by the Social Security Earnings Test, her $M B A$ is permanently reduced by the penalty rate. ${ }^{10}$ Benefits are adjusted according to the number of months between take-up and $F R A$. In the three-year period leading up to the $F R A$, each month take-up is brought forward adds $5 / 9$ of $1 \%$ to the cumulative penalty; prior to that each month adds $5 / 12$ of $1 \%$. The latter only applies to individuals born after $1937(F R A>65)$. Individuals claiming after the FRA earn DRCs. For those born in 1943 or later the total credit increases by $2 / 3$ of $1 \%$ for each month of delay. Delay past age 70 does not receive credit. For those born before 1943 the total credit increases at a constant $1 / 12$ to $5 / 8$ of $1 \%$ per month, depending on the birth year.

Table 1 provides a summary of the statutory adjustments for take-up at exact ages 62-70 for past, current, and future (planned) cohorts. Figure 1 provides graphs of the adjustment schedules for selected cohorts. The graphical representation facilitates comparison of how the shape of the adjustment schedule has changed across cohorts. The FRA and the penalties associated with early benefit take-up are the same for Americans born between 1917 and 1937: the FRA is age 65 and benefits are reduced by a constant $5 / 9$ of $1 \%$ per month (6.67\% per year) of earlier take-up. Following the 1983 Amendments, the FRA increased by 2 months per year across the 1938-1943 birth cohorts to (exact) age 66 .

A similar gradual increase is scheduled for the 1954-1960 cohorts, resulting in an FRA of age 67 for persons born after 1959. Individuals born after 1937 see benefits reduced by $5 / 9$ of $1 \%$ per month (6.67\% per year) of advanced take-up in the three years prior to $F R A$ and by $5 / 12$ of $1 \%$ per month $(5.0 \%$ per year) prior to that. In turn, the maximal penalty has increased from $20 \%(=5 / 9 * 1 \% * 36$

\footnotetext{
${ }^{9}$ Social Security uses the term Reduction Factor $(R F)$ to describe (monthly) benefits received expressed as a fraction of $P I A$, that is, $R F=1+r$.

${ }^{10}$ Early Social Security benefits are withheld for earnings above the limit at a rate of $50 \%$ for beneficiaries between age 62 and the January of the year in which they reach the $F R A$, and at a rate of 33\% from January of that year until the month they reach the FRA (SSA-S, 2005, p.19; SSA-S, 2005, Table 2.A18). In the latter period, the earnings limit is higher, $\$ 37,680$, compared with $\$ 14,160$ for the earlier period as of 2011 (SSA-S, 2011, Table 2.A29.1). Benefits withheld result in a reduction of the penalty (r) effective after $F R A$. Among the 1,543,000 Americans who claimed early benefits in 2010, 103,600 (6.71\%) had at least some withholding due to earnings (SSA-S, 2011, Table 6.B.5.1). Benítez-Silva and Heiland $(2007,2008)$ provide additional detail on the rules governing benefit withholding and discuss the implications for actuarial fairness. Until its abolition in 2000 there was also a post- $F R A$ Earnings Test.
} 
months) for Americans born before 1938 to $25 \%(=5 / 12 * 1 \% * 12$ months $+5 / 9 * 1 \% * 36$ months) for current cohorts of retirees (cohorts 1943-1959) and it is scheduled to reach $30 \%(=5 / 12 * 1 \% * 24$ months $+5 / 9 * 1 \% * 36$ months) for those born after 1959. ${ }^{11}$ The credit for delaying take-up past $F R A$ has increased more gradually. Cohorts born before 1925 see benefits increase by $1 / 4$ of $1 \%$ per month (3\% per year) of delay. For the 1925-1943 birth cohorts, this credit was raised by $1 / 24$ of $1 \%(0.5 \%$ per year) every other year: from $7 / 24$ of $1 \%$ per month (3.5\% per year) for the 1925 cohort to $16 / 24=2 / 3$ of $1 \%$ (8\% per year) for those born in 1943. Under current law, the credit will remain at this level.

The vast majority of retirement benefits are paid out to workers. However, individuals can also receive benefits as the spouse or widow(er) of an eligible insured worker. While the delayed retirement credit only exists for worker's benefits, spousal and widow(er) benefits face the same $F R A$ but somewhat different adjustment rules for early take-up. Specifically, spouse's benefits are reduced at a rate of 25/36 of 1 percent for each month in the three-year period prior to $F R A$ and at a rate of $5 / 12$ of 1 percent per month before that up to age 62. Survivor's benefits are payable as early as age 60 (age 50 if disabled) and the adjustment is a constant rate of reduction reaching a cumulative $28.5 \%$ penalty if benefits are claimed at age 60, compared to no penalty at $F R A$ and thereafter. As shown in Figure 1, the rate of adjustment is $5.7 \%$ per year for FRA 65 (cohorts 1919-1939), which is smaller than for either spouses and workers. ${ }^{12}$ Increases in the $F R A$ have similar effects on the early take-up schedule of spouses and survivors as in the case of workers. ${ }^{13}$

\footnotetext{
${ }^{11}$ According to Robert Myers, the chief actuary of the Social Security Administration from 1949 to 1970, the 5/9 of 1\% per month rate of reduction introduced in legislation from 1956 was determined using linear interpolation after establishing a $20 \%$ penalty at 62 given full benefits at FRA 65 at that time (see Myers and Schobel, 1990, p.295). During the deliberations for the 1983 Amendments, Congress apparently also considered a proposal to gradually increase the ERA in tandem with the FRA by (ultimately) two years to 64 . This would have shifted the penalty schedule without changing its curvature. Maintaining the rate of $5 / 9$ of $1 \%$ in the three-year period before $F R A$ and implementing a rate of $5 / 12$ of $1 \%$ per month before that may have been a compromise to keep the penalty percentages at the $E R A$ at fairly round numbers (25\% and $30 \%$ for FRA 66 and 67, respectively) when it became clear that increasing the $E R A$ was politically infeasible.

${ }^{12}$ The $F R A$ for widow(er)s is also increasing from 65 to 67 , but the increases affect the adjustment schedule of survivors with a two birth year delay. Consequently, the $F R A$ for widow(er)s born in 1939 is still exact age 65 .

${ }^{13}$ Approximately $6 \%$ of the individuals who collect some type of Old Age, Survivors, or Disability Insurance (OASDI) benefits receive them as spouses of entitled retirees. This percentage comes from the 2001 Public-Use Master Beneficiary Microdata provided by the Social Security Administration, a 1\% random sample of all beneficiaries in December of 2001. For further discussion of spousal and widow(er) benefits see Myers and Schobel (1990); Gustman and Steinmeier (1991, 2000); Coile et al. (2002); Coile (2003); Munnell and Soto (2005); Sun and Webb (2009).
} 


\subsection{Characteristics of Social Security's adjustment schedules}

There are three observations regarding the shape of the adjustment schedules that are most relevant to the analysis of actuarial fairness:

First, all schedules are piece-wise linear with at most two bend points ("nodes"), age $F R A$ and age FRA-3. (For cohorts 1917-1937, FRA equals exact age 65, resulting in only one bend point for workers). This implies that all schedules used by Social Security to date exhibit constant slopes over wide age intervals (age 62 to $F R A-3$ and $F R A-3$ to $F R A$ for workers and spouses; $F R A$ to 70 for workers only; 60 to $F R A$ for widowers only). As the $F R A$ increases the bend points are increasing, resulting in a wider early take-up penalty age range (62 to $F R A$ for workers and spouses; 60 to $F R A$ for widowers) and a shorter delayed retirement credit range for workers ( $F R A$ to 70$)$.

Second, for workers, the increases in the DRCs from 3\% per year of delay to $6.5 \%$ across the 1924 to 1937 cohort have changed the overall shape of the schedule from increasing at a non-increasing rate in take-up age (concave) for the 1917-1924 cohorts to almost perfectly linear for the 1937 cohort.

Third, the introduction of the $5 / 12$ of $1 \%$ per month (5\% per year) penalty between 62 and $F R A$ 3 for worker's and spouse's benefits, and increasing the credits for delayed retirement to $2 / 3$ of $1 \%$ per month ( $8 \%$ per year) for worker's, as part of the full retirement age reform, has caused the early penalty part to become flatter and the overall shape to become more convex (increasing at a constant or increasing rate) in take-up age. In turn, the adjustment schedules will tend to become even flatter at early take-up ages, as the $F R A$ increases to age 67 . This is particularly apparent for survivor's benefits, which will experience a drop in the annual penalty from $4.75 \%$ for $F R A 66$ to $4.07 \%$ for the designated FRA 67. 


\section{Assessing Actuarial Fairness}

\subsection{Fair benefit adjustment}

\section{Present value analysis}

An adjustment schedule is actuarially fair if it equalizes a person's expected present value (PV) of lifetime benefits for all take-up ages $E R A, E R A+1, \ldots, F R A, \ldots, M R A$. (Take-up past the "Maximum Retirement Age (MRA, currently 70)", is disregarded because delay past MRA does not earn DRCs.) Discounting all amounts to $E R A$, the definition for an adjustment schedule that is fair for individuals with survival risk profile, $S(a)$ (probability of living to age $a$ conditional on survival to age $a-1$, with $S(E R A)=1)$ and time discount rate, $\delta$, can be formally written as follows:

$$
\begin{aligned}
P V_{f} & \equiv \sum_{a=E R A}^{F R A+D} \prod_{i=E R A}^{a} S(i) \cdot\left(\frac{1}{1+\delta}\right)^{a-E R A} \cdot\left(1+r_{f}(E R A)\right) \cdot P I A \\
& \equiv \sum_{a=E R A+1}^{F R A+D} \prod_{i=E R A}^{a} S(i) \cdot\left(\frac{1}{1+\delta}\right)^{a-E R A} \cdot\left(1+r_{f}(E R A+1)\right) \cdot P I A \\
& \equiv \ldots \\
& \equiv \sum_{a=F R A}^{F R A+D} \prod_{i=E R A}^{a} S(i) \cdot\left(\frac{1}{1+\delta}\right)^{a-E R A} \cdot P I A \\
& \equiv \ldots \\
& \equiv \sum_{a=M R A}^{F R A+D} \prod_{i=E R A}^{a} S(i) \cdot\left(\frac{1}{1+\delta}\right)^{a-E R A} \cdot\left(1+r_{f}(M R A)\right) \cdot P I A .
\end{aligned}
$$

$F R A+D$ is the person's maximum age (set to 110 below) and $P V_{f}$ denotes the fair present value. The set of adjustments $r_{f}($.$) constitutes the actuarially fair schedule \left(r_{f}(F R A)=0\right.$ is imposed).

\section{Key properties of fair schedules}

Solving Equation (1), the fair adjustment for take-up at age $c<F R A$ ("early take-up") is:

$$
r_{f}(c)=-\frac{\sum_{a=c}^{F R A} \delta^{a-E R A} \prod_{i=E R A}^{a} S(i)}{\sum_{a=c}^{F R A} \delta^{a-E R A} \prod_{i=E R A}^{a} S(i)+\sum_{a=F R A}^{F R A+D} \delta^{a-E R A} \prod_{i=E R A}^{a} S(i)}<0 .
$$


Assuming $E R A=62$ and $F R A=65$, the fair penalties at exact ages 62, 63, and 64 are, respectively, $\frac{1+\delta \cdot S(63)+\delta^{2} \cdot S(63) S(64)}{1+\delta \cdot S(63)+\delta^{2} \cdot S(63) S(64)+A}, \frac{\delta \cdot S(63)+\delta^{2} \cdot S(63) \cdot S(64)}{\delta \cdot S(63)+\delta^{2} \cdot S(63) \cdot S(64)+A}$, and $\frac{\delta^{2} \cdot S(63) \cdot S(64)}{\delta^{2} \cdot S(63) \cdot S(64)+A}$, where $A \equiv \sum_{a=65}^{65+D} \delta^{a-62} \prod_{i=62}^{a} S(i)$.

Similarly, the theoretically fair adjustment for delayed take-up at age $c>F R A$ is:

$$
r_{f}(c)=\frac{\sum_{a=F R A}^{c} \delta^{a-E R A} \prod_{i=E R A}^{a} S(i)}{\sum_{a=F R A}^{c} \delta^{a-E R A} \prod_{i=E R A}^{a} S(i)+\sum_{a=F R A}^{F R A+D} \delta^{a-E R A} \prod_{i=E R A}^{a} S(i)}>0
$$

We observe that the fair adjustment schedule (i) increases at an increasing rate in take-up age and (ii) becomes flatter, turning clockwise in $F R A$, as longevity increases (see Appendix I for the proof). Intuitively, the (strictly) convex shape of the fair schedule through $F R A$ results from the fact that the effect of a reduction in the cumulative adjustment on lifetime benefits will be the greater the earlier the takeup age, because it is applied to a longer time period. If longevity increases, actuarial fairness requires lower adjustments for early and delayed take-up because the adjustments have a greater lifetime effect. (It is easy to see that an increase in the discount rate, $\delta$, has the opposite effect of mortality decline.)

\subsection{Measures of actuarial fit and favorability}

To quantify the extent to which actual adjustment schedules are actuarially fair, we calculate coefficients of variation $(\mathrm{CV})$ of the following form (in decimal):

$$
C V_{i} \equiv \frac{\frac{1}{B-A-1} \sqrt{\sum_{c=A}^{B}\left[P V(c)-P V_{F R A}\right]^{2}}}{P V_{F R A}}
$$

The $C V$ is a standard measure of the relative dispersion of a distribution around a given value (typically the mean). Equation (4) measures the deviation of the discounted benefit stream for take-up between ages $A$ and $B$ from its fair value, $P V_{F R A}$. We calculate the $C V$ (in \%) for the early adjustments $(A=$ $E R A, B=F R A)$, the delayed adjustments $(A=F R A, B=M R A)$, and the overall schedule $(A=E R A$, $B=M R A) .{ }^{14}$

\footnotetext{
${ }^{14}$ The number of comparisons or data points entering Equation (4) depends on $A, B$ and $F R A$; for cohorts subject to interim FRAs it will be incremented by 1.
} 
We also introduce a measure of the "actuarial favorability" of the adjustments. Specifically, we calculate the proportion of "positive deviations," that is, the ratio of the sum of the squared distances between $P V_{F R A}$ and $P V(c)$ when $P V(c)>P V_{F R A}$ to the total deviation. This measures the favorability of the actual adjustments relative to the fair adjustments from the beneficiaries' perspective. ${ }^{15}$ Graphically, if, for example, the early and the delayed adjustments lie above the fair schedule, then the actual penalties and $D R C$ s are $100 \%$ favorable. Regardless of claiming age, beneficiaries would be better off under the actual schedule, while the SST fund would prefer implementing the fair schedule. (The overall \% favorable is a weighted average of the early and delayed \%.)

\subsection{Empirical setup}

We focus on average beneficiaries born in 1917-1960 and analyze males and females separately. Available cohort life table data up to 2008 from the Human Mortality Database (http://www.mortality.org/) are used to estimate the survival profiles past age 60. In our "Baseline Mortality" scenario, we assume that cohort mortality remains constant at 2008 levels. We contrast this lower-bound case with a "Low Mortality" scenario that extrapolates past improvements in mortality (e.g., Olshansky et al. 2005). ${ }^{16}$

Our baseline discounting scenario assumes a constant annual discount rate of $3 \%$. The value is chosen to be consistent with averages used by the Actuarial Office of Social Security (AOSS) based on (real) yields of long-dated U.S. treasury bonds (see Girola, 2005). We also analyze a variable (real) discounting scenario, where the benefit flows of each cohort are discounted according to the (real) interest rate on long-term treasuries prevailing at the time. To that end, we constructed the time series

\footnotetext{
${ }^{15}$ To obtain the absolute benefit, we can simply multiply the measure by the $C V$ (or the standard deviation about $P V_{F R A}$ to get a dollar amount).

${ }^{16}$ Specifically, using death rates after age 60 for male and female birth cohorts 1900-1948, we estimated logistic models of mortality with cohort trends. Specifically, we assume that the death rate, $\mu_{a}(i)$, at exact age $a$ for the average individual in birth cohort $i$ (cohort 1900 is denoted by $i=1$ ) takes the form: $\mu_{a}(i)=\frac{\beta \gamma^{a} i}{1+\beta \gamma^{a} i^{\delta}}$. This logistic form fits mortality at older ages particularly well (e.g., Thatcher et al., 1998). We have enhanced the basic model with a quadratic age term and a cohort trend to account for mortality declines across generations. Convenient for estimation, the logit of $\mu_{a}(i)$ is linear in age, age squared, and cohort: $\operatorname{logit}\left(\mu_{a}(i)\right)=\ln (\beta)+\ln \left(\gamma_{1}\right) \cdot a+\ln \left(\gamma_{2}\right) \cdot a^{2}+\ln (\delta) \cdot i=\beta^{\prime}+\gamma_{1}^{\prime} \cdot a+\gamma_{2}^{\prime} \cdot a^{2}+\delta^{\prime} \cdot i$ where $\beta^{\prime} \equiv \ln (\beta), \gamma_{1}^{\prime} \equiv$ $\ln \left(\gamma_{1}\right), \gamma_{2}^{\prime} \equiv \ln \left(\gamma_{2}\right)$ and $\delta^{\prime} \equiv \ln (\delta)$ are parameters to be estimated. Our OLS estimates (standard errors in parentheses) for men are $\beta_{M}^{\prime}=-4.27665$ (0.23952), $\gamma_{M, 1}^{\prime}=-0.03217$ (0.00644), $\gamma_{M, 2}^{\prime}=0.00074$ (0.00004) and $\delta_{M}^{\prime}=-0.01843$ (0.00014), and for women $\beta_{W}^{\prime}=-5.03173$ (0.10002), $\gamma_{W, 1}^{\prime}=-0.04329(0.00265), \gamma_{W, 2}^{\prime}=0.00090(0.00002)$, and $\delta_{W}^{\prime}=-0.09984$ (0.0002). R-squared (adjusted) is 0.996 for males and 0.998 for females.
} 
of the real interest rate shown in Figure 2, based on 1954-2012 data on average annual yields of 20-year treasuries available from the Federal Reserve (www.federalreserve.gov) deflated by the CPI-U. Values after 2012 are imputed with the long-run average value of 2.68\%. ${ }^{17}$ This rate and our 3\% baseline case closely match values Social Security uses in its long term solvency forecast (intermediate case), where real interest rates stabilize at $2.9 \%$ in 2020 (SSA-T, 2009, p.101). ${ }^{18}$

Discounting benefit flows at "risk-free" interest rates may be appropriate from the perspective of the Social Security Trust (SST). By law, income to the SST can only be invested in securities with federal interest and principal guarantees. ${ }^{19}$ These rates may not coincide with rates that are realistic for average Americans trying to solve their retirement problem (see Duggan and Soares, 2002). Individuals are likely to discount future moneys more heavily than SST fund managers would for the following reasons: higher (expected) rates of return on capital, individual-level risks related to health (e.g., morbidity and mortality) and economic wellbeing (e.g., unemployment and borrowing constraints), and subjective time preference motivations (impatience). Since we are primarily interested in the investment perspective of Social Security, we make the case of a moderate annual (real) rate of 3\% our baseline scenario. We do explore the discount rate sensitivity by looking at a high discounting scenario where we set the annual discount rate to $9 \%$, consistent with evidence of typical discount rates among retirees. ${ }^{20}$

Some additional observations are in order. We focus on take-up at exact ages $62,63, \ldots$, FRA, $, \ldots, 70$. With the exception of the cohorts with an "interim" FRA (1938-1942 and 1955-1959), this means that the calculations are based on round ages. However, the results for take-up during interim months

\footnotetext{
${ }^{17}$ We also obtained the 1968-2007 interest rate time series data (based on long-dated treasuries) used by Social Security from AOSS. Before 1999, only 5-year averages are reported, resulting in a substantial loss of variation compared to our annual data. However, we calculated a long-run average real rate of $2.8 \%$ in the AOSS data, which is close to our average of $2.68 \%$. (See Figure 2.)

${ }^{18}$ Duggan and Soares (2002) use within-sample mortality estimates and focus on a constant annual time discount rate of 3\% (some sensitivity analysis using 1\% and 5\% is conducted). Queisser and Whitehouse (2006) assume a 2\% discount rate. Shoven and Slavov (2014) focus on the $2.9 \%$ and $0 \%$ case. In addition to the three discounting scenarios discussed here, we also looked at alternative discount rates, including an extreme case of $0 \%$ discounting. The spreadsheets with our calculations are available from the authors upon request. The spreadsheets are customizable and can be used to analyze any discount rate or mortality scenario.

${ }^{19}$ The majority of SST funds are invested in "special-issue" bonds that mimic conventional long-dated treasuries. At the end of 2011, the average (nominal) annual interest rate of the OASI special-issues was $4.17 \%$ and the average time to maturity was 7.42 years (see http://www.ssa.gov/oact/ProgData/investheld.html).

${ }^{20}$ The value of $9 \%$ is motivated by estimates of the distribution of discount rates among older Americans provided by Gustman and Steinmeier (2002).
} 
can easily be approximated. Differences in the real pension wealth across cohorts do not impact our comparisons. This is because we are modeling discounted money flows (risk-neutral linear utility retirees) rather than utility flows of risk-averse consumers. As discussed in the previous paragraph this is the appropriate perspective for Social Security. ${ }^{21}$ After age 60, the PIA is indexed to the price level using a cost-of-living-adjustment. We only consider the case of constant (real) PIAs. Given that the majority of beneficiaries claim between age 62 and 64 (see SSA-S, 2011, Table 6.B5), increases in the PIA after age 62 due to a higher earnings year replacing a lower earnings year in the past are not typical.

\section{Main Results}

Table 2 summarizes the fair adjustment schedules of average mortality male and female beneficiaries born in years 1918, 1928, 1937, 1943, and 1960 for the three discounting scenarios. (The adjustments based on the low mortality alternative scenario are shown in parentheses.) For example, in the baseline discount rate scenario (constant 3\%), the total actuarially fair reduction for take-up at age 62 is $21.62 \%$ for men born in 1918.

The results illustrate the theoretical properties of the fair schedule discussed in Section 3.1. The fair adjustments are found to be notably greater for males than for females, reflecting the gender-gap in longevity that favors women. Similarly, we observe a decline in the adjustments across birth cohorts 1917-1937. It reflects the impact of increasing life expectancy, holding $F R A$ constant. The flattening of the fair schedule is more pronounced for men who experienced greater gains in longevity than women.

As expected, the increase in the FRA from 65 to 66 across birth cohorts 1937-1943 has a profound effect on the fair schedule. A higher FRA implies higher penalties before $F R A$ and lower credits thereafter. The scheduled increase in the FRA to age 67 is expected to have the same effect. Discounting at $3 \%$, the fair penalties at 62 are $30.96 \%$ for men and $28.33 \%$ for women born in 1960, compared to $25.33 \%$ for men and $23.11 \%$ for women born in 1943 . The results also confirm that the greater the

\footnotetext{
${ }^{21}$ Average (real) PIAs have increased somewhat over time, primarily due to real wage gains, rising labor supply (especially among women), and program expansion. Benítez-Silva and Yin (2009, p.7, Table 3) report that the average monthly benefits (in constant 2005 dollars) among retirees of age 62 increased from \$1,066 in 1994 to \$1,135 in 2004.
} 
discount rate the greater the fair adjustments.

\subsection{Beneficiaries born 1917-1943: towards actuarial fairness}

Figures 3-5 show the trends in the actuarial fit based on the $C V$ for our three discount rate scenarios. In all scenarios, we observe a meaningful improvement in the overall actuarial fit across cohorts. Among men, applying a 3\% discount rate, $C V^{\text {Overall }}$ declined from $5.1 \%$ for the 1918 cohort to $0.77 \%$ for the 1943 cohort. For women, it declined from $4.0 \%$ to $0.45 \%$ across the same cohorts. The dramatic increases in the DRCs across cohorts 1924-1943 are the key contributing factor. For men, the $C V^{\text {Delayed }}$ declined from $8.14 \%$ to $1.51 \%$ across cohorts $1918-1943$. The corresponding values for women are $6.39 \%$ and $0.50 \%$. Historically, the early adjustments are much closer to the fair form than the $D R C$ s and they did not change as dramatically. For men, assuming 3\% discounting, we observe a decline in the $C V^{\text {Early }}$ from $1.12 \%$ to $0.29 \%$ across cohorts $1918-1937$. For women, however, the early fit worsened slightly up to the 1937 generation. This pattern is consistent with studies that have looked at more selected cohorts (e.g., Duggan and Soares, 2002). The corresponding fair penalty at 62 declined from $21.62 \%$ for men born in 1918 to $19.58 \%$ for men born in 1937 . For women, the respective penalty declined from $18.53 \%$ to $17.77 \%$ over the same period. The statutory penalty at 62 is $20 \%$, a level closely matching the fair percentage for the 1937 male cohort but exceeding the fair value for the corresponding female cohort. (See Tables 1 and 2.)

To better understand the gender differences, consider Figure 6, which depicts the actual and the fair schedule for cohorts 1918 and 1943 under baseline discounting. It is clear that the statutory penalties were too high for average mortality men born in 1918, while they were close to fair for women with average longevity born in 1918. As life expectancy increased, the fair penalties declined, causing the fit for men to improve while the fit for women worsened. The current penalties are slightly too high for female retirees today, while they are very close to fair for men. The current $D R C$ of $8 \%$, on the other hand, remains below fair levels for males, while it matches the fair value for women, who continue to enjoy lower mortality than men, fairly well. 
The results for variable discounting are very similar. ${ }^{22}$ In the high discount rate scenario (9\%), which is meant to capture the time preference of average beneficiaries, the fit improves for both male and female beneficiaries up to the 1937-1938 birth cohort. ${ }^{23}$ The high discount rate yields a steeper (and more curved) adjustment schedule, offsetting the impact of life expectancy and resulting in penalties that are less than actuarially fair even for average mortality females born in 1917.

Figure 7 illustrates the contribution of mortality to the actuarial fit for male cohorts (baseline $3 \%$ discounting). One set of graphs shows the deviations from the fair form assuming that mortality rates are constant at the level of the 1918 birth cohort. The result show that the improvements in fit would have been significantly smaller for men in the absence of gains in life expectancy. Specifically, we estimate that the deviation from fairness of the overall schedule would have fallen from $5.10 \%$ to $1.61 \%$ across the 1918-1943 birth cohorts. This compares to a decline in the average deviation from 5.10\% to $0.89 \%$ across the same birth cohorts in the baseline case. Consequently, we may attribute $17.1 \%$ of the total observed improvement in actuarial fit across male beneficiaries born between 1918 and 1943 to rising life expectancy. (This figure becomes $23.0 \%$ in our low mortality scenario.) As discussed above, life expectancy gains have made the fit worse for women since the adjustments tend to be too high for women, owing to their greater longevity. (We present additional evidence on the effects of life expectancy and the shape of the adjustment schedule on actuarial fairness in Appendix II.)

The "Low Mortality" graphs in Figure 7 show $C V$ s for our alternative (low) mortality scenario discussed above. Not surprisingly these results are more sensitive to the mortality assumptions among recent cohorts. We see greater adherence to actuarial fairness for the $D R C$ s and the overall adjustment schedule for men when mortality is projected to continue to decline. These improvements reflect the

\footnotetext{
${ }^{22}$ In the early 1990s, Social Security actuaries claimed that rising real interest rates had effectively offset longevity gains (based on personal conversation). As shown in Figure 2, the long-term trend in annual real interest 1954-2012 is positive but the series is very volatile. Since the trend reversed in the mid-1980s it is unclear to us how actuarial fairness could have been maintained. Using unpublished interest and mortality data from the actuaries, a 2004 policy brief by Jivan (2004, p.2, Figure 3) reports that the ratio of the present values of the benefit stream for take-up at age 62 to take-up at 65 was close to 1 in the 1990s, a value interpreted as "perfect age neutrality," and similar to levels found in the 1990s. A recent policy brief by Munnell and Sass (2012) updates this analysis for data up to 2010. The discount rate in the present value calculation is based on a constant real interest rate but it is not clear what the underlying average interest rates are. The two real interest rates reported are for the years 1960 and 2004 (1.4\% and 3\%) and do not match our values for these years $(2.34 \%$ and $2.38 \%$ ), as shown in Figure 2.

${ }^{23}$ The kink in the $C V$ s during the transition from 65 to 66 and 66 to 67 reflects the additional pair that enters the calculation for interim FRAs.
} 
fact that the adjustments tend to be too low for men; rising longevity mitigates this effect by lowering the fair adjustments. For women the actuarial fit of the early adjustments and the schedule overall is generally worse under low mortality, reflecting the fact that the actual penalties are already very close to or even above the fair values for the early female cohorts (e.g., beneficiaries born in 1918 as shown in Figure 6).

Figure 8 shows results from "actuarial favorability" analysis under baseline discounting. The bigger the dot (bubble), the more the actual adjustments benefit the average-mortality beneficiary at the expense of the SST fund. As discussed in Section 3.2, the underlying measure of "percentage favorable" ranges from 0 to $100 \%$. We find that delayed take-up has been unfavorable ( $0 \%$ favorable) for males across generations. This implies that, for average male retirees who discount benefits at 3\%, there has never been an actuarial incentive to delay claiming past $F R A$. For women born prior to 1943, the delayed take-up schedule has also been entirely unfavorable. For female cohorts subject to $F R A$ 66, delayed take-up is largely unfavorable as well (18.1\% favorable) and we predict a similar situation for future female retirees facing $F R A 67$. While early take-up has been actuarially favorable for the average male throughout the history of the system (100\% favorable), it has generally been unfavorable for females ( $<2 \%$ favorable). As discussed above, for women, the penalties tend to be too large and the credits too small to be actuarially fair for average-mortality. ${ }^{24}$

\subsection{Fairness in the future: retirement age reform}

During the second phase of the 1983 Amendments the $F R A$ will increase to 67 across beneficiaries born in 1955-1960. The three-year age range prior to $F R A$ penalizing earlier take-up at 5/9 of $1 \%$ per month will shift by one year and the flatter range will extend to exact age 64 (see Figure 1). We predict that this transformation will have little impact on actuarial fairness. As shown in Figure 3, the overall deviation from the fair form is predicted to be $0.60 \%$ for male and $0.45 \%$ for female beneficiaries born in 1960

\footnotetext{
${ }^{24}$ We can make useful ceteris paribus deductions about other groups of beneficiaries by comparing their mortality demographics to that of the average male retiree. For example, we can infer that for women with below average longevityplacing them on par with average males, early take-up has been actuarially favorable. For women with above average lifespan take-up after $F R A$ has become more favorable as the DRCs rose to $8 \%$ annually.
} 
under baseline conditions. This compares to $0.53 \%$ for men and $0.45 \%$ for women born in 1943 . If longevity continues to increase, as we predict in our "Low Mortality" scenario, then we expect a slightly worse overall fit for the 1960 females $\left(C V_{f, 1960}^{\text {Overall }}=0.76 \%\right)$ while the fit for men would be about the same $\left(C V_{m, 1960}^{\text {Overall }}=0.59 \%\right)$. Under variable discounting (which applies a lower, constant $2.68 \%$ discount rate after 2012), we also predict a modestly improved overall fit for men while the fit worsens marginally for women. In the high discounting (9\%) scenario, we find that the early adjustments fit the 1960 male and female cohorts worse than the cohorts facing FRA 66, while the DRCs fit slightly better (see Figure 5). The overall fit is predicted to worsen as the $F R A$ increases because of the relatively poorer fit of penalty part that is expanding. 25

The discussion in Myers and Schobel (1990, Footnote 3, p.296) suggests that Congress also considered a gradual increase of the $E R A$ in tandem with the $F R A$ at the time of the deliberations for the 1983 Amendments. Had this been implemented, the ERA for the 1943 and 1960 cohorts would have been 63 and 64 , respectively. In that case, there would have been no need to introduce the $5 / 12$ of $1 \%$ reduction per month and the slope of the penalty schedules faced by beneficiaries born in 1943 and 1960 would have been a constant 5/9 of $1 \%$ reduction per month throughout. Experiment 1 in Table 3 describes this counterfactual adjustment schedule for $F R A 67$, the corresponding actuarially fair adjustments, and the estimated fit for the 1960 cohort under 3\% discounting and different mortality developments. By construction, the actual and the fair adjustments to benefits are identical to the currently planned $F R A$ 67 schedule in the age range 64 to 70 . We note that the fit of the early adjustments and the overall fit can differ from the FRA 67 schedule as the present values for take-up at age 62 and 63 no longer enter the calculations. Since the delayed take-up schedule fits marginally better than the early schedule for women, while the reverse is true for men under constant mortality, the described increase in the $E R A$ from 62 to 64 would result in a small improvement in the overall fit for women and a slightly worse overall fit for men. If mortality rates decline at their historic pace, both women and men would experience a better fit.

In December 2010, the National Commission on Fiscal Responsibility and Reform (NCFRR) pro-

\footnotetext{
${ }^{25}$ Assuming the extreme case of $0 \%$ discounting, we find a similar pattern. In this case, the overall deviation from the fair form is $1.56 \%$ for men and $2.26 \%$ for women, respectively.
} 
posed steps to address the long-run solvency problems of Social Security. The commission recommended that retirement benefits be reduced by indexing the retirement ages to approximate gains in life expectancy. Specifically, the NCFRR suggested that the ERA and the FRA be increased by one month every two years after $F R A$ reaches age 67 under current law. According to their calculations, the $E R A$ would increase to 63 by 2046 and 64 by 2070 while the $F R A$ would reach 68 and 69 in those years. Increases in the FRA beyond age 67 will alter the adjustment schedule by extending the early take-up range at the expense of the $D R C$ s. Table 3 shows the results of raising $F R A$ to 69 with $E R A$ at 62 (Experiment 2) and ERA at 64 (Experiment 3), implemented for alternative mortality scenarios of the 1960 cohort and 3\% discounting. We focus on this cohort to simplify the comparison. Given the 1983 precedent, increasing only the $F R A$ is probably the most politically feasible way to achieve benefit reductions. Increasing the $E R A$ is extremely inequitable as it cuts access to benefits for poorer individuals who are less likely to continue working past age 62 and less able to afford postponement. We assume that in either case Congress maintains the current monthly reductions of $5 / 9$ of $1 \%$ in the three-year period ending in FRA (here: 66-69) and 5/12 of 1\% per month before that (here: 62/64-66).

For women, we predict that the fit would be no worse than FRA 67 in either reform scenario. For constant mortality, the early schedule deviates from the fair form by $0.48 \%$ and $0.20 \%$, respectively, in Experiments 2 and 3 (low mortality: $1.06 \%$ and $0.70 \%$, respectively). This compares to a $C V^{\text {Early }}$ of $0.69 \%$ (1.19\%) for the FRA 67 schedule (reference). For men, we predict an improvement in the fit of the early adjustments if longevity rises (see Table 3). (The overall fit for women is predicted to worsen slightly in Experiment 2 if mortality declines, due to the wider penalty age range that fits worse than the DRCs. The effect is similar for men.)

We propose two alternative schedules for a FRA age 69 that better adhere to the convex curvature requirement (see Section 3.1). In Experiment 4 the monthly penalty increases geometrically from 5/14 of $1 \%$ per additional month of earlier take-up between age 62 and 63,5/13 of $1 \%$ between 63 and 64 , to $5 / 8$ of $1 \%$ between 68 and 69 . Between $F R A$ and age 70 , the monthly credit is $5 / 7$ of $1 \%$. Experiment 5 models a flatter version of this schedule, using marginal monthly penalties that increase from $5 / 15$ to $5 / 9$ of $1 \%$ before $F R A$ and a monthly credit of $5 / 8$ of $1 \%$ after $F R A$. The cumulative adjustments for 
both schedules are shown in Table 3 .

Assuming constant longevity, the steeper schedule in Experiment 4 provides a better overall fit for men $(0.81 \%)$ than the FRA 69 schedule in Experiment 2, while the fit for women is the same $(0.42 \%)$. If average lifespans continue to lengthen as predicted, the flatter schedule in Experiment 5 will fit both male $(0.48 \%)$ and (particularly) female $(0.21 \%)$ beneficiaries better than the FRA 69 schedule. The schedule in Experiment 5 is also the most actuarially favorable for claimers, with near $100 \%$ actuarial favorability overall for either sex. This is due to the fact that the fair penalties are consistently greater than the actual penalties (see Table 3).

\subsection{Spousal and widow(er) benefits}

As discussed in Section 2, and illustrated for selected cohorts in Figure 1, spousal and survivor benefits are adjusted differently than worker benefits: The $D R C$ does not apply and the penalty is steeper. Survival benefits can be claimed as early as 60, resulting in a wider take-up age range compared to the other benefit types. Also, the penalty schedule for widow(er)s has no bend point and thus flattens in a similar fashion at all ages as FRA increases. Focusing on average females and 3\% discounting, the early take-up schedule deviates from the fair form by approximately $3.1 \%$ for spouses and $2.5 \%$ for widows born in 1918. This indicates a worse fit than for worker benefits for the same demographic. As the FRA increased to age 66 , the fit improves to $1.77 \%$ deviation under baseline mortality $(1.76 \%$ if mortality declines) for survivor benefits in the 1945 cohort. For the 1943 females the adjustments to spousal benefits fit slightly worse than the 1918 females. The designated increases in the $F R A$ to 67 will likely result in adjustments that are further from the fair form for either benefit type. We predict the adjustment to survivor's benefits to deviate by $2.54 \%$ under baseline mortality $(2.11 \%$ if mortality declines) for the 1962 female birth cohort. The corresponding value for spousal benefits is a deviation of $3.21 \%$ (3.69\% if mortality declines). 


\section{Discussion and Conclusion}

A key result of the preceding analysis is that the actuarial fit of Social Security's benefit adjustment schedules for workers has improved significantly across beneficiaries born in 1917-1943. The improvement is primarily the result of the rising DRC across the 1924-1943 birth cohorts and the widening of the penalty age range, which, for average mortality men, is closer to actuarial fairness than the $D R C$. Currently, the penalties for early take-up are closer to actuarially fair for average mortality males than females, while the reverse holds for the $D R C$ s. We show that the penalties tend to be slightly too high (actuarially unfavorable) for women, while the $D R C$ s are too small for men. This gender pattern is likely to continue: further declines in old-age mortality — causing the fair schedule to become flatterwill improve the actuarial fit for male beneficiaries but not for females. Our findings substantiate claims by Myers and Schobel (1990, p.295) that the penalties associated with the FRA 67 adjustment schedule will be "reasonably close to the theoretically correct values" and the corresponding DRCs will be “approximately correct” for workers retiring in 2030.

Historically, for the range of plausible discount rates considered here, the adjustment schedule provided a strong disincentive for individuals with average life expectancy to delay take-up past $F R A$ because of the less than actuarially fair DRCs. The incentive to claim early, on the other hand, was favorable or neutral to average beneficiaries. The increases in the $D R C$ s have made claiming after FRA more attractive while take-up before $F R A$ has become relatively less attractive because of the demographic trends. (As discussed, this development has not been slowed meaningfully by the introduction of flatter adjustments before age FRA-3.) Empirically, it is well documented that the majority of beneficiaries claim benefits before reaching FRA (e.g., Benítez-Silva and Yin, 2009). However, it is noteworthy that, consistent with the changing fundamentals discussed here, the percentage of retirement benefit awards made at ages 62-64 has declined to $57.8 \%$ for men (63\% for women) in 2010 from $66.1 \%$ for men (72.9\% for women) in 1990 (see SSA-S, 2011, Table 6.B5). ${ }^{26}$

Our finding that the adjustments are close to actuarially fair for discount rates consistent with his-

\footnotetext{
${ }^{26}$ Excluding disability conversions the corresponding percentages in 1990 and 2010 are, respectively, $73.5 \%(80 \%)$ and $66.4 \%(71.8 \%)$ for men (women).
} 
toric (average) levels of (real) interest rates of long-dated treasuries suggests that the fact that the vast majority of beneficiaries claim benefits early has little long-term impact on Social Security outlays. The primary risk in this annuity problem is the evolution of the real interest rate, namely inflation and investment risk. If, for example, real interest rates were to remain at their current historically low levels, then average beneficiaries who claim early would provide some financial relief to the system, as they accept benefits that are less than actuarially fair. (We note that Social Security likely prefers delayed take-up from a "pay-as-you-go" or annual budgetary perspective. Also, since benefit take-up is closely aligned with labor supply behavior, early claimers tend to contribute less than later claimers in payroll taxes at retirement age.)

The previous discussion points to a potentially important systemic benefit of adopting the fair adjustment schedule: Setting an adjustment policy that makes benefit outlays independent of take-up behavior on average will likely reduce the volatility of total outlays (the risk faced by the Social Security Trust resulting from the uncertain age at benefit take-up). Depending on the objective, however, policy makers may elect a different adjustment policy. For example, if the goal is to encourage longer working lives, a steeper than actuarially fair schedule could be implemented to induce more delayed retirement. This, however, will likely conflict with the goal of benefit equity: A steeper schedule (maintaining FRA) will lower benefits for early claimers who may have below-average longevity and retirement wealth. 


\section{Appendix I: Proof}

This appendix provides a proof of the result stated in Section 3.1 that the actuarially fair adjustments are smaller when life expectancy is greater. We derive the effect of an increase in the period-survival risk, $S(j)$ (for $j \in\{E R A, \ldots, F R A+D\}$ ), on the fair adjustment at early take-up age $c<F R A, r_{f}(c)$. We need to show that $r_{f}(c)$, which is negative for $c<F R A$, increases (that is, it moves closer to 0 ) as the periodsurvival risk increases. The fair adjustment schedule for early take-up (see Equation (2)) can be written as $r(c)=-\frac{A}{A+B}$, where $A \equiv \sum_{a=c}^{F R A} \delta^{a-E R A} \prod_{i=E R A}^{a} S(i)>0$ and $B \equiv \sum_{a=F R A+1}^{F R A+D} \delta^{a-E R A} \prod_{i=E R A}^{a} S(i)>0$. Define $R \equiv \sum_{a=c}^{j-1} \delta^{a-E R A} \prod_{i=E R A}^{a} S(i)>0$ if $j>c$ and $R \equiv 0$ if $j \leq c$.

$\frac{d r(c)}{d S(j)}=-\frac{\frac{d A}{d S(j)} B-A \frac{d B}{d S(j)}}{(A+B)^{2}}$

Case $1(j>F R A)$ :

$=-\frac{0 \cdot B-A \frac{B}{S(j)}}{(A+B)^{2}}=-\frac{-A \frac{B}{S(j)}}{(A+B)^{2}}>0$

Case $2(j \leq F R A)$ :

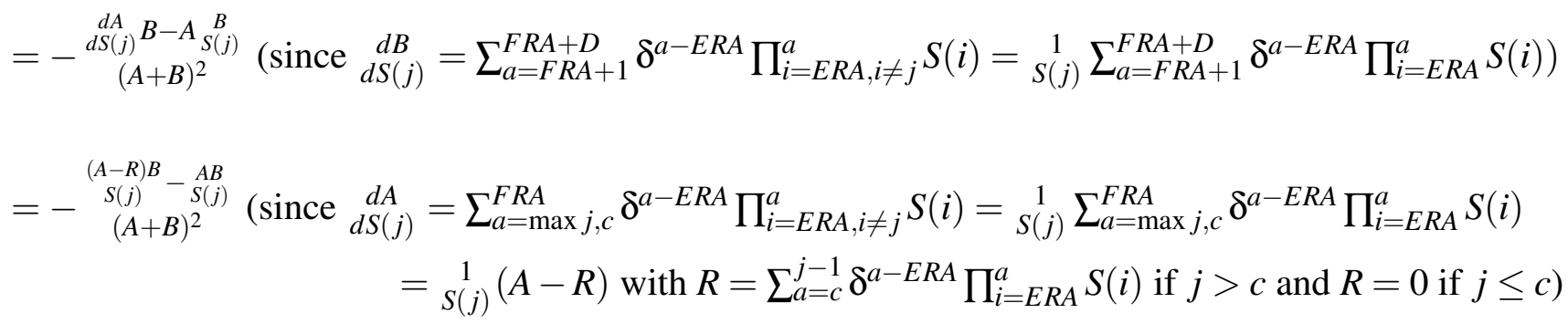
$=\underset{S(j)}{B} R \geq 0$ (holds with strict inequality if $j>c$ ).

q.e.d. 


\section{Appendix II: Fairness decomposition analysis}

To further analyze the effect of the adjustment schedule and longevity on actuarial fairness, we conducted multivariate regression analyses. Using Equation (4) we calculated the overall deviation from actuarial fairness across cohorts 1917-1960 by sex, mortality scenario, and interest rate environment. We considered 10 constant interest rate profiles, ranging from $0 \%$ to $9 \%$. We regressed the log of $\%$ overall deviation on economic factors (interest rate and interest rate squared), demographics (life expectancy at 62), and variables characterizing the adjustment policy (cumulative credit at various take-up ages). (In this model, we cannot identify the effect of gender separately because all gender heterogeneity is captured by the longevity variable.)

Table Appendix II shows results for three specifications, separately for baseline mortality and low mortality. Model 1 is the most parsimonious policy specification, only accounting for credits at age 62 and 70. Model 2 controls for credits at interim ages identified by the schedule changes that apply to the 1917-1960 cohorts. Model 3 adds an interaction terms between longevity and credit at age 62 and 70 to the specification in Model 1. Collectively, the three sets of factors (plus a constant terms) explain over $80 \%$ of the variation in actuarial fairness (in logs), indicating that this regression provides a good linear approximation to the true model (Equation (4)).

We find that the policy variables and longevity combined contribute about $44 \%$ of the observed changes in fairness across cohorts. The discount rate explains the remaining 56\%. At up to $10 \%$ of the total explained variation, changes in life expectancy are making a meaningful contribution to the actuarial fit, consistent with the results in Section 4.1. At a given discount rate, an adjustment schedule is marginally closer to actuarial fairness for cohorts with greater longevity. According to Model 1, under baseline mortality conditions, a one year increase in life expectancy improves the fit by $4 \%$. The effect is more pronounced in the low mortality case, perhaps capturing the greater variability in lifespans in these data. The analysis also confirms the earlier result that a higher discount rate is associated with a worse fit, on average. Policy makers can use the estimated relationships in Table Appendix II as a quick way to predict how close a particular schedule is to actuarial fairness under different interest rates for a given demographic. 


\section{References}

Belloni, M., and C. Maccheroni (2006). "Actuarial Neutrality when Longevity Increases: An Application to the Italian Pension System," Center for Research on Pensions and Welfare Policies Working Paper 47/06.

Benítez-Silva, H., and F. Heiland (2007). "The Social Security Earnings Test and Work Incentives," Journal of Policy Analysis and Management, 26-3 527-555.

Benítez-Silva, H., and F. Heiland (2008). "Early Claiming of Social Security Benefits and Labor Supply Behavior of Older Americans," Applied Economics, 40-23 2969-2985.

Benítez-Silva, H., and N. Yin (2009). "An Empirical Study of The Effects of Social Security Reforms on Benefit Claiming Behavior and Receipt Using Public-Use Administrative Microdata," Social Security Bulletin, 693 77-95.

Blinder, A., Gordon, R., and D. Wise (1980). "Reconsidering the Work Disincentive Effects of Social Security," National Tax Journal, 33-4 431-442.

Burkhauser, R.V. (1980). "The Early Acceptance of Social Security: An Asset Maximization Approach," Industrial and Labor Relations Review, 33-4 484-492.

Coile, C., P. Diamond, J. Gruber, and A. Jousten (2002). "Delays in Claiming Social Security Benefits," Journal of Public Economics, 84-3 357-385.

Coile, C. (2003). "Retirement Incentives and Couples' Retirement Decisions," Working Paper No.4. Chestnut Hill, MA: Center for Retirement Research at Boston College.

Coile, C., and J. Gruber (2007). "Future Social Security Entitlements and the Retirement Decision," The Review of Economics and Statistics, 89-2 234-246.

Crawford, V.P., and D.M. Lilien (1981). "Social Security and the Retirement Decision," Quarterly Journal of Economics, 96-3 505-529.

Duggan, J.E., and C.J. Soares (2002). "Actuarial Nonequivalence in Early and Delayed Social Security Benefit Claims," Public Finance Review, 30-3 188-207.

French, E. (2005). "The Effects of Health, Wealth, and Wages on Labour Supply and Retirement Behaviour," Review of Economic Studies, 72 395-427.

Girola, J. (2005). "The Long-term Real Interest Rate for Social Security," Department of Treasury Research Paper No. 2005-02.

Gruber, J., and P. Orszag (2003). "Does the Social Security Earnings Test Affect Labor Supply and Benefits Receipt?” National Tax Journal, 56-4 755-773.

Gruber, J., and D. Wise (2005). "Social Security Programs and Retirement around the World: Fiscal Implications," NBER Working Paper No. 11290.

Gustman, A. L., and T.L. Steinmeier (1991). “Changing the Social Security Rules for Work after 65," Industrial and Labor Relations Review, 44 733-745.

Gustman, A.L., and T.L. Steinmeier (2000). "Retirement in a Family Context: A Structural Model for Husbands and Wives," Journal of Labor Economics, 18 503-545. 
Gustman, A.L., and T.L. Steinmeier (2002). "The Social Security Early Entitlement Age in a Structural Model of Retirement and Wealth,” NBER Working Paper No. 9183.

Jivan, N.A. (2004). "How Can the Actuarial Reduction for Social Security Early Retirement be Right?" Just the Facts on Retirement Issues, July 2004, Number 11, Center for Retirement Research at Boston College.

Liu, L., and A. Rettenmaier (2006). "Work and Retirement," The National Center for Policy Analysis Policy Backgrounder No. 162.

Mirer, T.W. (1998). "The Optimal Time to File for Social Security Benefits," Public Finance Review, 26(6) 611-636.

Munnell, A.H., and M. Soto (2005). "Why do Women Claim Social Security Benefits so Early?," Center for Retirement Research at Boston College Working Paper 2005-35.

Munnell, A.H., and S.A. Sass (2012). "Can the Actuarial Reduction for Social Security Early Retirement Still be Right?" Just the Facts on Retirement Issues, March 2012, Number 6, Center for Retirement Research at Boston College.

Myers, R.J. (1993). Social Security. Fourth Edition. Pension Research Council and University of Pennsylvania Press.

Myers, R.J., and B.D. Schobel (1990). "Early-Retirement Reduction and Delayed-Retirement Increase Factors under U.S. Social Security Law,” Transactions, XLII 295-320.

Olshansky, S.J., Passaro, D.J., Hershow, R.C., Layden, J., Carnes, B.A., Brody, J., Hayflick, L., Butler, R.N., Allison, D.B., and D.S. Ludwig (2005). "A Potential Decline in Life Expectancy in the United States in the 21st Century," New England Journal of Medicine, 352-11 1138-1145.

Queisser, M, and E. Whitehouse (2006). "Neutral or Fair? Actuarial Concepts and Pension-System Design." OECD Social Employment, and Migration Working Paper No. 40.

Rust, J., and C. Phelan (1997). "How Social Security and Medicare Affect Retirement Behavior in a World of Incomplete Markets," Econometrica, 65 781-831.

Shoven, J., and S. Slavov (2014). "Does It Pay to Delay Social Security?" Journal of Pension Economics and Finance, 13 121-144.

Sun, W., and A. Webb (2009). "How Much do Households Really Lose by Claiming at 62?" Center for Retirement Research at Boston College Working Paper 2009-11.

SSA-S (various years). Annual Statistical Supplement to the Social Security Bulletin. http://www.ssa.gov/policy/docs/statcomps/supplement/

SSA-T (2009). The 2009 Annual Report of the Board of Trustees of the Federal Old-Age and Survivors Insurance and Federal Disability Insurance Trust Funds. Washington, D.C.

Thatcher, A.R., Kannisto, V., and J.W. Vaupel (1998). The force of mortality at ages 80 to 120. Odense: Odense University Press (Monographs on Population Aging, 5).

van der Klaauw, W., and K.I. Wolpin (2008). "Social Security and the Retirement and Savings Behavior of low-income Households," . Journal of Econometrics, 145 21-42. 


\section{Table 1: Workers' Benefit Adjustment Schedule ${ }^{a}$, All Cohorts}

\begin{tabular}{|c|c|c|c|c|c|c|c|c|c|}
\hline \multirow[b]{2}{*}{ Birth Cohort } & \multicolumn{9}{|c|}{ Exact Age at Benefit Take-up } \\
\hline & 62 & 63 & 64 & 65 & 66 & 67 & 68 & 69 & 70 \\
\hline & \multicolumn{9}{|c|}{$F R A 65$} \\
\hline $1917-1924$ & -20.00 & -13.33 & -6.67 & 0.00 & 3.00 & 6.00 & 9.00 & 12.00 & 15.00 \\
\hline $1925-1926$ & -20.00 & -13.33 & -6.67 & 0.00 & 3.50 & 7.00 & 15.00 & 14.00 & 17.50 \\
\hline $1927-1928$ & -20.00 & -13.33 & -6.67 & 0.00 & 4.00 & 8.00 & 12.00 & 16.00 & 20.00 \\
\hline 1929-1930 & -20.00 & -13.33 & -6.67 & 0.00 & 4.50 & 9.00 & 13.50 & 18.00 & 22.50 \\
\hline $1931-1932$ & -20.00 & -13.33 & -6.67 & 0.00 & 5.00 & 10.00 & 15.00 & 20.00 & 25.00 \\
\hline 1933-1934 & -20.00 & -13.33 & -6.67 & 0.00 & 5.50 & 11.00 & 16.50 & 22.00 & 27.50 \\
\hline $1935-1936$ & -20.00 & -13.33 & -6.67 & 0.00 & 6.00 & 12.00 & 18.00 & 24.00 & 30.00 \\
\hline \multirow[t]{2}{*}{1937} & -20.00 & -13.33 & -6.67 & 0.00 & 6.50 & 13.00 & 19.50 & 26.00 & 32.50 \\
\hline & \multicolumn{9}{|c|}{$F R A 65$ and 2 months } \\
\hline \multirow[t]{2}{*}{1938} & -20.83 & -14.44 & -7.78 & -1.11 & 5.42 & 11.92 & 18.42 & 24.92 & 31.42 \\
\hline & \multicolumn{9}{|c|}{$F R A 65$ and 4 months } \\
\hline \multirow[t]{2}{*}{1939} & -21.67 & -15.56 & -8.89 & -2.22 & 4.67 & 11.67 & 18.67 & 25.67 & 32.67 \\
\hline & \multicolumn{9}{|c|}{$F R A 65$ and 6 months } \\
\hline 1940 & \multicolumn{9}{|c|}{$F R A 65$ and 8 months } \\
\hline \multirow[t]{2}{*}{1941} & -23.33 & -17.78 & -11.11 & -4.44 & 2.50 & 10.00 & 17.50 & 25.00 & 32.50 \\
\hline & \multicolumn{9}{|c|}{$F R A 65$ and 10 months } \\
\hline \multirow[t]{2}{*}{1942} & -24.17 & -18.89 & -12.22 & -5.55 & 1.25 & 8.75 & 16.25 & 23.75 & 31.25 \\
\hline & \multicolumn{9}{|c|}{$F R A 66$} \\
\hline 1943-1954 & \multicolumn{9}{|c|}{$F R A 66$ and 2 months } \\
\hline \multirow[t]{2}{*}{1955} & -25.83 & -20.83 & -14.44 & -7.78 & -1.11 & 6.67 & 14.67 & 22.67 & 30.67 \\
\hline & \multicolumn{9}{|c|}{$F R A 66$ and 4 months } \\
\hline \multirow[t]{2}{*}{1956} & -26.67 & -21.67 & -15.56 & -8.89 & -2.22 & 5.33 & 13.33 & 21.33 & 29.33 \\
\hline & \multicolumn{9}{|c|}{$F R A 66$ and 6 months } \\
\hline \multirow[t]{2}{*}{1957} & -27.50 & -22.50 & -16.67 & -10.00 & -3.33 & 4.00 & 12.00 & 20.00 & 28.00 \\
\hline & \multicolumn{9}{|c|}{$F R A 66$ and 8 months } \\
\hline \multirow[t]{2}{*}{1958} & -28.33 & -23.33 & -17.78 & -11.11 & -4.44 & 2.67 & 10.67 & 18.67 & 26.67 \\
\hline & \multicolumn{9}{|c|}{$F R A 66$ and 10 months } \\
\hline 1959 & -29.17 & -24.17 & -18.89 & -12.22 & -5.55 & 1.33 & 9.33 & 17.33 & 25.33 \\
\hline $1960+$ & -30.00 & -25.00 & -20.00 & -13.33 & $\begin{array}{r}F R A 67 \\
-6.67\end{array}$ & 0.00 & 8.00 & 16.00 & 24.00 \\
\hline
\end{tabular}

Notes: ${ }^{a}$ The percentage by which benefits are increased at a given take-up age relative to take-up at FRA. Americans born in 1937 are the last cohort facing an FRA of exactly 65 years. Those born in 1943 are in the first generation subject to an FRA of exactly 66 years. The 1960 birth cohort is the first cohort facing an FRA of 67 years. 


\begin{tabular}{|c|c|c|c|c|c|c|c|c|c|}
\hline \multirow[t]{2}{*}{ Discount Rate } & \multicolumn{9}{|c|}{ Exact Age at Benefit Take-up } \\
\hline & 62 & 63 & 64 & 65 & 66 & 67 & 68 & 69 & 70 \\
\hline & \multicolumn{9}{|c|}{1918 Birth Cohort (62 in 1980 ) } \\
\hline & & & & & Men & & & & \\
\hline Constant 3\% & $-21.62(-21.61)$ & $-15.18(-15.18)$ & $-8.02(-8.01)$ & 0.00 & $9.00(8.99)$ & $19.12(19.11)$ & $30.57(30.55)$ & $43.55(43.52)$ & $58.33(58.28)$ \\
\hline Constant 9\% & $-31.69(-31.68)$ & $-22.60(-22.60)$ & $-12.13(-12.13)$ & 0.00 & $14.10(14.09)$ & $30.53(30.52)$ & $49.75(49.74)$ & $72.32(72.31)$ & $98.92(98.90)$ \\
\hline \multirow[t]{2}{*}{ Real Interest ${ }^{b}$} & \multirow{2}{*}{\multicolumn{9}{|c|}{$\begin{array}{l}8.53(8.53) \\
\text { Women }\end{array}$}} \\
\hline & & & & & & & & & \\
\hline Constant 3\% & $-18.53(-18.54)$ & $-12.93(-12.93)$ & $-6.78(-6.78)$ & 0.00 & $7.49(7.49)$ & $15.79(15.79)$ & $25.01(25.02)$ & $35.31(35.32)$ & $46.84(46.85)$ \\
\hline Constant 9\% & $-28.80(-28.80)$ & $-20.39(-20.40)$ & $-10.86(-10.86)$ & 0.00 & $12.40(12.40)$ & $26.59(26.59)$ & $42.89(42.89)$ & $61.67(61.67)$ & 83.38 (83.39) \\
\hline \multirow[t]{3}{*}{ Real Interest $^{b}$} & $-19.31(-19.32)$ & $-13.36(-13.37)$ & $-6.80(-6.80)$ & 0.00 & $6.94(6.94)$ & $14.15(14.16)$ & $21.90(21.91)$ & $30.70(30.71)$ & $40.79(40.81)$ \\
\hline & \multicolumn{9}{|c|}{1928 Birth Cohort (62 in 1990) } \\
\hline & \multicolumn{9}{|c|}{ Men } \\
\hline Constant 3\% & $-20.39(-20.34)$ & $-14.28(-14.24)$ & $-7.51(-7.49)$ & 0.00 & $8.37(8.34)$ & $17.71(17.65)$ & $28.19(28.08)$ & $39.98(39.81)$ & $53.29(53.04)$ \\
\hline Constant 9\% & $-30.59(-30.58)$ & $-21.76(-21.75)$ & $-11.64(-11.63)$ & 0.00 & $13.42(13.41)$ & $28.92(28.90)$ & $46.91(46.87)$ & $67.85(67.78)$ & $92.29(92.19)$ \\
\hline \multirow[t]{2}{*}{ Real Interest ${ }^{b}$} & $-19.46(-19.41)$ & $-13.50(-13.46)$ & $-6.99(-6.97)$ & 0.00 & $7.89(7.87)$ & $16.03(15.97)$ & $25.16(25.06)$ & $35.26(35.12)$ & $45.91(45.71)$ \\
\hline & \multicolumn{9}{|c|}{ Women } \\
\hline Constant 3\% & $-18.08(-18.09)$ & $-12.60(-12.61)$ & $-6.59(-6.60)$ & 0.00 & $7.26(7.27)$ & $15.28(15.31)$ & $24.17(24.21)$ & $34.06(34.11)$ & $45.08(45.16)$ \\
\hline Constant 9\% & $-28.41(-28.43)$ & $-20.10(-20.11)$ & $-10.69(-10.69)$ & 0.00 & $12.16(12.18)$ & $26.04(26.07)$ & $41.93(41.98)$ & $60.17(60.26)$ & $81.17(81.31)$ \\
\hline \multirow[t]{3}{*}{ Real Interest ${ }^{b}$} & $-17.07(-17.09)$ & $-11.78(-11.79)$ & $-6.07(-6.08)$ & 0.00 & $6.78(6.79)$ & $13.69(13.71)$ & $21.35(21.39)$ & $29.75(29.81)$ & $38.52(38.60)$ \\
\hline & \multirow{2}{*}{\multicolumn{9}{|c|}{$\begin{array}{c}1937 \text { Birth Cohort (62 in 1999) } \\
\text { Men }\end{array}$}} \\
\hline & & & & & & & & & \\
\hline Constant 3\% & $-19.58(-19.32)$ & $-13.69(-13.50)$ & $-7.19(-7.08)$ & 0.00 & $7.98(7.84)$ & $16.86(16.55)$ & $26.80(26.25)$ & $37.94(37.11)$ & $50.51(49.30)$ \\
\hline Constant 9\% & $-29.73(-29.63)$ & $-21.10(-21.02)$ & $-11.26(-11.21)$ & 0.00 & $12.91(12.84)$ & $27.76(27.60)$ & $44.91(44.61)$ & $64.78(64.30)$ & $87.91(87.16)$ \\
\hline \multirow[t]{2}{*}{ Real Interest ${ }^{b}$} & $-18.38(-18.13)$ & $-12.80(-12.62)$ & $-6.70(-6.60)$ & 0.00 & $7.13(7.01)$ & $15.26(15.97)$ & $24.40(23.91)$ & $35.38(34.61)$ & $47.53(46.40)$ \\
\hline & \multicolumn{9}{|c|}{ Women } \\
\hline Constant 3\% & $-17.77(-17.73)$ & $-12.37(-12.34)$ & $-6.47(-6.46)$ & 0.00 & $7.12(7.09)$ & $14.96(14.92)$ & $23.65(23.57)$ & $33.29(33.16)$ & $44.03(43.86)$ \\
\hline Constant 9\% & $-28.09(-28.10)$ & $-19.85(-19.86)$ & $-10.54(-10.55)$ & 0.00 & $11.97(11.98)$ & $25.60(25.62)$ & $41.16(41.20)$ & $58.99(59.05)$ & $79.50(79.59)$ \\
\hline \multirow[t]{3}{*}{ Real Interest ${ }^{b}$} & $-16.65(-16.61)$ & $-11.55(-11.52)$ & $-6.02(-6.01)$ & 0.00 & $6.36(6.34)$ & $13.55(13.50)$ & $21.56(21.49)$ & $31.09(30.97)$ & $41.51(41.34)$ \\
\hline & \multicolumn{9}{|c|}{1943 Birth Cohort $(62 \text { in } 2005)^{e}$} \\
\hline & \multicolumn{9}{|c|}{ Men } \\
\hline Constant 3\% & $-25.33(-24.57)$ & $-19.92(-19.28)$ & $-13.95(-13.47)$ & $-7.34(-7.07)$ & 0.00 & $8.18(7.83)$ & $17.34(16.53)$ & $27.63(26.22)$ & $39.24(37.06)$ \\
\hline Constant 9\% & $-37.54(-37.16)$ & $-29.94(-29.60)$ & $-21.28(-21.01)$ & $-11.37(-11.21)$ & 0.00 & $13.09(12.85)$ & $28.20(27.62)$ & $45.74(44.64)$ & $66.17(64.33)$ \\
\hline \multirow[t]{2}{*}{ Real Interest ${ }^{b}$} & $-24.75(-23.98)$ & $-19.53(-18.92)$ & $-13.83(-13.34)$ & $-7.46(-7.17)$ & 0.00 & $7.25(6.93)$ & $15.99(15.23)$ & $27.12(25.70)$ & $40.23(37.90)$ \\
\hline & \multicolumn{9}{|c|}{ Women } \\
\hline Constant 3\% & $-23.11(-22.91)$ & $-18.10(-17.94)$ & $-12.62(-12.50)$ & $-6.61(-6.54)$ & 0.00 & $7.30(7.21)$ & $15.38(15.17)$ & $24.36(24.00)$ & $34.38(33.80)$ \\
\hline Constant 9\% & $-35.62(-35.58)$ & $-28.30(-28.26)$ & $-20.02(-19.99)$ & $-10.65(-10.63)$ & 0.00 & $12.13(12.10)$ & $25.99(25.91)$ & $41.88(41.71)$ & $60.16(59.84)$ \\
\hline \multirow[t]{2}{*}{ Real Interest ${ }^{b}$} & $-22.55(-22.34)$ & $-17.76(-17.59)$ & $-12.49(-12.36)$ & $-6.71(-6.64)$ & 0.00 & $6.46(6.38)$ & 14.19 (13.99) & $23.90(23.52)$ & $35.18(34.55)$ \\
\hline & \multicolumn{9}{|c|}{1960 Birth Cohort (62 in 2022) ${ }^{f}$} \\
\hline Constant 3\% & $-30.96(-27.77)$ & $-25.97(-23.15)$ & $-20.45(-18.11)$ & $-14.35(-12.61)$ & $-7.56(-6.60)$ & 0.00 & $8.46(7.26)$ & $17.98(15.26)$ & $28.71(24.10)$ \\
\hline Constant 9\% & $-44.74(-42.53)$ & $-38.03(-35.98)$ & $-30.38(-28.58)$ & $-21.62(-20.22)$ & $-11.57(-10.75)$ & 0.00 & $13.37(12.23)$ & $28.88(26.19)$ & $46.94(42.16)$ \\
\hline Real Interest ${ }^{b}$ & $-30.19(-26.96)$ & $-25.31(-22.45)$ & $-19.93(-17.56)$ & $-13.97(-12.22)$ & $-7.36(-6.39)$ & 0.00 & $8.22(7.01)$ & $17.46(14.74)$ & $27.86(23.27)$ \\
\hline & & & & & Women & & & & \\
\hline Constant 3\% & $-28.33(-27.09)$ & $-23.67(-22.57)$ & $-18.57(-17.66)$ & $-12.96(-12.29)$ & $-6.80(-6.43)$ & 0.00 & $7.53(7.07)$ & $15.90(14.86)$ & $25.24(23.47)$ \\
\hline Constant 9\% & $-42.57(-41.77)$ & $-36.05(-35.30)$ & $-28.67(-28.01)$ & $-20.31(-19.80)$ & $-10.82(-10.52)$ & 0.00 & $12.36(11.94)$ & $26.53(25.54)$ & $42.83(41.07)$ \\
\hline Real Interest ${ }^{b}$ & $-27.55(-26.29)$ & $-23.00(-21.89)$ & $-18.03(-17.11)$ & $-12.59(-11.91)$ & $-6.60(-6.22)$ & 0.00 & $7.30(6.83)$ & $15.40(14.35)$ & $24.43(22.66)$ \\
\hline
\end{tabular}


Table 2: Fair Adjustment Schedule ${ }^{a}$, Men and Women, Selected Cohorts

\begin{tabular}{|c|c|c|c|c|c|c|c|c|c|}
\hline \multirow[t]{2}{*}{$\overline{\text { Discount Rate }}$} & \multicolumn{9}{|c|}{ Exact Age at Benefit Take-up } \\
\hline & 62 & 63 & 64 & 65 & 66 & 67 & 68 & 69 & 70 \\
\hline & \multicolumn{9}{|c|}{1918 Birth Cohort (62 in 1980) } \\
\hline & & & & & Men & & & & \\
\hline Constant 3\% & $-21.62(-21.61)$ & $-15.18(-15.18)$ & $-8.02(-8.01)$ & 0.00 & $9.00(8.99)$ & $19.12(19.11)$ & $30.57(30.55)$ & $43.55(43.52)$ & $58.33(58.28)$ \\
\hline Constant 9\% & $-31.69(-31.68)$ & $-22.60(-22.60)$ & $-12.13(-12.13)$ & 0.00 & $14.10(14.09)$ & $30.53(30.52)$ & $49.75(49.74)$ & $72.32(72.31)$ & $98.92(98.90)$ \\
\hline Real Interest ${ }^{b}$ & \multicolumn{9}{|c|}{$\begin{array}{l}8.53(8.53) \\
\text { Women }\end{array}$} \\
\hline Constant 3\% & $-18.53(-18.54)$ & $-12.93(-12.93)$ & $-6.78(-6.78)$ & 0.00 & $7.49(7.49)$ & $15.79(15.79)$ & $25.01(25.02)$ & $35.31(35.32)$ & $46.84(46.85)$ \\
\hline Constant 9\% & $-28.80(-28.80)$ & $-20.39(-20.40)$ & $-10.86(-10.86)$ & 0.00 & $12.40(12.40)$ & $26.59(26.59)$ & $42.89(42.89)$ & $61.67(61.67)$ & $83.38(83.39)$ \\
\hline \multirow[t]{2}{*}{ Real Interest ${ }^{b}$} & $-19.31(-19.32)$ & $-13.36(-13.37)$ & $-6.80(-6.80)$ & 0.00 & $6.94(6.94)$ & $14.15(14.16)$ & $21.90(21.91)$ & $30.70(30.71)$ & $40.79(40.81)$ \\
\hline & \multicolumn{9}{|c|}{1928 Birth Cohort (62 in 1990) } \\
\hline Constant 3\% & $-20.39(-20.34)$ & $-14.28(-14.24)$ & $-7.51(-7.49)$ & 0.00 & $8.37(8.34)$ & $17.71(17.65)$ & $28.19(28.08)$ & $39.98(39.81)$ & 53.29 (53.04) \\
\hline Constant 9\% & $-30.59(-30.58)$ & $-21.76(-21.75)$ & $-11.64(-11.63)$ & 0.00 & $13.42(13.41)$ & $28.92(28.90)$ & $46.91(46.87)$ & $67.85(67.78)$ & $92.29(92.19)$ \\
\hline \multirow[t]{2}{*}{ Real Interest ${ }^{b}$} & $-19.46(-19.41)$ & $-13.50(-13.46)$ & $-6.99(-6.97)$ & 0.00 & $7.89(7.87)$ & $16.03(15.97)$ & $25.16(25.06)$ & $35.26(35.12)$ & $45.91(45.71)$ \\
\hline & \multicolumn{9}{|c|}{ Women } \\
\hline Constant 3\% & $-18.08(-18.09)$ & $-12.60(-12.61)$ & $-6.59(-6.60)$ & 0.00 & $7.26(7.27)$ & $15.28(15.31)$ & $24.17(24.21)$ & $34.06(34.11)$ & $45.08(45.16)$ \\
\hline Constant 9\% & $-28.41(-28.43)$ & $-20.10(-20.11)$ & $-10.69(-10.69)$ & 0.00 & $12.16(12.18)$ & $26.04(26.07)$ & $41.93(41.98)$ & $60.17(60.26)$ & $81.17(81.31)$ \\
\hline \multirow[t]{3}{*}{ Real Interest ${ }^{b}$} & $-17.07(-17.09)$ & $-11.78(-11.79)$ & $-6.07(-6.08)$ & 0.00 & $6.78(6.79)$ & $13.69(13.71)$ & $21.35(21.39)$ & $29.75(29.81)$ & $38.52(38.60)$ \\
\hline & \multirow{2}{*}{\multicolumn{9}{|c|}{$\begin{array}{l}1937 \text { Birth Cohort (62 in 1999) } \\
\text { Men }\end{array}$}} \\
\hline & & & & & & & & & \\
\hline Constant 3\% & $-19.58(-19.32)$ & $-13.69(-13.50)$ & $-7.19(-7.08)$ & 0.00 & $7.98(7.84)$ & $16.86(16.55)$ & $26.80(26.25)$ & $37.94(37.11)$ & $50.51(49.30)$ \\
\hline Constant 9\% & $-29.73(-29.63)$ & $-21.10(-21.02)$ & $-11.26(-11.21)$ & 0.00 & $12.91(12.84)$ & $27.76(27.60)$ & $44.91(44.61)$ & $64.78(64.30)$ & $87.91(87.16)$ \\
\hline \multirow[t]{2}{*}{ Real Interest ${ }^{b}$} & \multirow{2}{*}{\multicolumn{9}{|c|}{ Women }} \\
\hline & & & & & & & & & \\
\hline Constant 3\% & $-17.77(-17.73)$ & $-12.37(-12.34)$ & $-6.47(-6.46)$ & 0.00 & $7.12(7.09)$ & $14.96(14.92)$ & $23.65(23.57)$ & $33.29(33.16)$ & $44.03(43.86)$ \\
\hline Constant 9\% & $-28.09(-28.10)$ & $-19.85(-19.86)$ & $-10.54(-10.55)$ & 0.00 & $11.97(11.98)$ & $25.60(25.62)$ & $41.16(41.20)$ & $58.99(59.05)$ & $79.50(79.59)$ \\
\hline \multirow[t]{3}{*}{ Real Interest ${ }^{b}$} & $-16.65(-16.61)$ & $-11.55(-11.52)$ & $-6.02(-6.01)$ & 0.00 & $6.36(6.34)$ & $13.55(13.50)$ & $21.56(21.49)$ & $31.09(30.97)$ & $41.51(41.34)$ \\
\hline & \multicolumn{9}{|c|}{1943 Birth Cohort $(62 \text { in } 2005)^{e}$} \\
\hline & \multicolumn{9}{|c|}{ Men } \\
\hline Constant 3\% & $-25.33(-24.57)$ & $-19.92(-19.28)$ & $-13.95(-13.47)$ & $-7.34(-7.07)$ & 0.00 & $8.18(7.83)$ & $17.34(16.53)$ & $27.63(26.22)$ & $39.24(37.06)$ \\
\hline Constant 9\% & $-37.54(-37.16)$ & $-29.94(-29.60)$ & $-21.28(-21.01)$ & $-11.37(-11.21)$ & 0.00 & $13.09(12.85)$ & $28.20(27.62)$ & $45.74(44.64)$ & $66.17(64.33)$ \\
\hline \multirow[t]{2}{*}{ Real Interest $t^{b}$} & $-24.75(-23.98)$ & $-19.53(-18.92)$ & $-13.83(-13.34)$ & $-7.46(-7.17)$ & 0.00 & $7.25(6.93)$ & $15.99(15.23)$ & $27.12(25.70)$ & $40.23(37.90)$ \\
\hline & \multicolumn{9}{|c|}{ Women } \\
\hline Constant 3\% & $-23.11(-22.91)$ & $-18.10(-17.94)$ & $-12.62(-12.50)$ & $-6.61(-6.54)$ & 0.00 & $7.30(7.21)$ & $15.38(15.17)$ & $24.36(24.00)$ & $34.38(33.80)$ \\
\hline Constant 9\% & $-35.62(-35.58)$ & $-28.30(-28.26)$ & $-20.02(-19.99)$ & $-10.65(-10.63)$ & 0.00 & $12.13(12.10)$ & $25.99(25.91)$ & $41.88(41.71)$ & $60.16(59.84)$ \\
\hline \multirow[t]{2}{*}{ Real Interest ${ }^{b}$} & $-22.55(-22.34)$ & $-17.76(-17.59)$ & $-12.49(-12.36)$ & $-6.71(-6.64)$ & 0.00 & $6.46(6.38)$ & $14.19(13.99)$ & $23.90(23.52)$ & $35.18(34.55)$ \\
\hline & \multicolumn{9}{|c|}{$\begin{array}{c}1960 \text { Birth Cohort (62 in 2022) } \\
\text { Men }\end{array}$} \\
\hline Constant 3\% & $-30.96(-27.77)$ & $-25.97(-23.15)$ & $-20.45(-18.11)$ & $-14.35(-12.61)$ & $-7.56(-6.60)$ & 0.00 & $8.46(7.26)$ & $17.98(15.26)$ & $28.71(24.10)$ \\
\hline & $-44.74(-42.53)$ & $-38.03(-35.98)$ & $-30.38(-28.58)$ & $-21.62(-20.22)$ & $-11.57(-10.75)$ & 0.00 & $13.37(12.23)$ & $28.88(26.19)$ & $46.94(42.16)$ \\
\hline \multirow[t]{2}{*}{ Real Interest ${ }^{b}$} & $-30.19(-26.96)$ & $-25.31(-22.45)$ & $-19.93(-17.56)$ & $-13.97(-12.22)$ & $-7.36(-6.39)$ & 0.00 & $8.22(7.01)$ & $17.46(14.74)$ & 27.86 (23.27) \\
\hline & \multicolumn{9}{|c|}{ Women } \\
\hline Constant 3\% & $-28.33(-27.09)$ & $-23.67(-22.57)$ & $-18.57(-17.66)$ & $-12.96(-12.29)$ & $-6.80(-6.43)$ & 0.00 & $7.53(7.07)$ & $15.90(14.86)$ & $25.24(23.47)$ \\
\hline Constant 9\% & $-42.57(-41.77)$ & $-36.05(-35.30)$ & $-28.67(-28.01)$ & $-20.31(-19.80)$ & $-10.82(-10.52)$ & 0.00 & $12.36(11.94)$ & $26.53(25.54)$ & $42.83(41.07)$ \\
\hline Real Interest $^{b}$ & $-27.55(-26.29)$ & $-23.00(-21.89)$ & $-18.03(-17.11)$ & $-12.59(-11.91)$ & $-6.60(-6.22)$ & 0.00 & $7.30(6.83)$ & $15.40(14.35)$ & 24.43 (22.66) \\
\hline
\end{tabular}

Notes: ${ }^{a}$ The numbers represent the percentage by which full benefits would have to be adjusted for a given take-up age and discounting scenario. The adjustments are actuarially fair in the sense that they force the expected present value of the lifetime benefit stream (discounted to age 62) initiated at the given age to be the same as for take-up at $F R A$. The numbers in parentheses represent the fair adjustment calculated using our projected mortality ("Low Mortality" scenario). ${ }^{b}$ For the 1970-2012 period we use the actual annual real interest rate of long term treasuries. After 2012 we use a constant annual rate of $2.68 \%$, the average over the $1954-2012$ period. 
Table 3: Retirement Age Reform Analysis, Men and Women, 1960 Cohort, $3 \%$ Discounting

\begin{tabular}{|c|c|c|c|c|c|c|c|c|c|c|c|c|}
\hline Schedule & 62 & 63 & 64 & $\begin{array}{l}\text { Exact Age at Benefi } \\
65\end{array}$ & Take-up 66 & 67 & 68 & 69 & 70 & Early & $\begin{array}{l}\% \text { (Favorable in } \% \\
\text { Delayed }\end{array}$ & $b^{a}{ }^{a}$ Overall \\
\hline Reference: $E R A \mathbf{6 2}, F R A \mathbf{6 7}$ & & & & & & & & & & & & \\
\hline Actual & $\begin{array}{c}-30.00 \\
-5 / 12 * 24-5 / 9 * 36\end{array}$ & $\begin{array}{l}-25.00 \\
-510^{*} 125 * 36\end{array}$ & $\begin{array}{l}-20.00 \\
5 / 9 * 36\end{array}$ & -13.33 & -6.67 & 0.00 & 8.00 & 16.00 & 24.00 & & & \\
\hline $\begin{array}{l}\text { (detail) } \\
\text { Fair-Men (Baseline) }^{b}\end{array}$ & & $-5 / 12 * 12-5 / 9 * 36$ & $-5 / 9 * 36$ & $-5 / 9 * 24$ & $-5 / 9 * 12$ & 0.00 & $2 / 3 * 12$ & $2 / 3 * 24$ & $2 / 3 * 36$ & & & \\
\hline $\begin{array}{l}\text { Fair, Men (Baseline) } \\
\text { Fair Women (Baseline) }\end{array}$ & $\begin{array}{l}-30.96 \\
-28.33\end{array}$ & -25.97 & -20.45 & -14.35 & -7.56 & 0.00 & 8.46 & 17.98 & 28.71 & $0.50(100.00)$ & $1.35(0.00)$ & $0.60(27.76)$ \\
\hline Fair, Women (Baseline) & -28.33 & -23.67 & -18.57 & -12.96 & -6.80 & 0.00 & 7.53 & 15.90 & 25.24 & $0.69(1.70)$ & $0.36(16.53)$ & $0.45(3.06)$ \\
\hline Fair, Men (Low Mortality) & -27.77 & -23.15 & -18.11 & -12.61 & -6.60 & 0.00 & 7.26 & 15.26 & 24.10 & $0.92(3.19)$ & $0.32(99.23)$ & $0.59(7.10)$ \\
\hline Fair, Women (Low Mortality) & -27.09 & -22.57 & -17.66 & -12.29 & -6.43 & 0.00 & 7.07 & 14.86 & 23.47 & $1.19(4.00)$ & $0.46(100.00)$ & $0.76(8.99)$ \\
\hline Exp. 1: $E R A$ 64, $F R A 67$ & & & & & & & & & & & & \\
\hline Actual & & & -20.00 & -13.33 & -6.67 & 0.00 & 8.00 & 16.00 & 24.00 & & & \\
\hline (detail) & & & $5 / 9 * 36$ & $-5 / 9 * 24$ & $-5 / 9 * 12$ & 0.00 & $2 / 3 * 12$ & $2 / 3 * 24$ & $2 / 3 * 36$ & & & \\
\hline Fair, Men (Baseline) & 0.00 & 0.00 & -20.45 & -14.35 & -7.56 & 0.00 & 8.46 & 17.98 & 28.71 & $0.55(100.00)$ & $1.35(0.00)$ & $0.73(14.03)$ \\
\hline Fair, Women (Baseline) & 0.00 & 0.00 & -18.57 & -12.96 & -6.80 & 0.00 & 7.53 & 15.90 & 25.24 & $0.61(6.06)$ & $0.36(16.53)$ & $0.35(8.82)$ \\
\hline Fair, Men (Low Mortality) & 0.00 & 0.00 & -18.11 & -12.61 & -6.60 & 0.00 & 7.26 & 15.26 & 24.10 & $0.82(11.32)$ & $0.32(99.23)$ & $0.44(22.84)$ \\
\hline Fair, Women (Low Mortality) & 0.00 & 0.00 & -17.66 & -12.29 & -6.43 & 0.00 & 7.07 & 14.86 & 23.47 & $1.03(14.72)$ & $0.46(100.00)$ & $0.57(29.06)$ \\
\hline Exp. 2: $E R A$ 62, FRA 69 & & & & & & & & & & & & \\
\hline $\begin{array}{l}\text { Actual } \\
\text { AnA }\end{array}$ & -40.00 & -35.00 & -30.00 & -25.00 & -20.00 & -13.33 & -6.67 & 0.00 & 8.00 & & & \\
\hline (detail) & $-5 / 12 * 48-5 / 9 * 36$ & $-5 / 12 * 36-5 / 9 * 36$ & $-5 / 12 * 24-5 / 9 * 36$ & $-5 / 12 * 12-5 / 9 * 36$ & $-5 / 9 * 36$ & $-5 / 9 * 24$ & $-5 / 9 * 12$ & 0.00 & $2 / 3 * 12$ & & & \\
\hline Fair, Men (Baseline) & -41.48 & -37.25 & -32.57 & -27.40 & -21.65 & -15.24 & -8.06 & 0.00 & 9.10 & $1.07(100.00)$ & $1.01(0.00)$ & $0.95(98.23)$ \\
\hline Fair, Women (Baseline) & -37.89 & -33.85 & -29.42 & -24.57 & -19.23 & -13.72 & -7.22 & 0.00 & 8.06 & $0.48(5.04)$ & $0.05(0.00)$ & $0.42(5.03)$ \\
\hline Fair, Men (Low Mortality) & -37.40 & -33.39 & -29.03 & -24.26 & -19.05 & -13.24 & -6.94 & 0.00 & 7.68 & $0.78(4.26)$ & $0.30(100.00)$ & $0.68(4.55)$ \\
\hline Fair, Women (Low Mortality) & -36.81 & -32.90 & -28.63 & -23.99 & -18.90 & -12.93 & -6.78 & 0.00 & 7.50 & $1.06(5.82)$ & $0.46(100.00)$ & $0.93(6.19)$ \\
\hline Exp. 3: $E R A$ 64, FRA 69 & & & & & & & & & & & & \\
\hline Actual & & & -30.00 & -25.00 & -20.00 & -13.33 & -6.67 & 0.00 & 8.00 & & & \\
\hline (detail) & & & $-5 / 12 * 24-5 / 9 * 36$ & $-5 / 12 * 12-5 / 9 * 36$ & $-5 / 9 * 36$ & $-5 / 9 * 24$ & $-5 / 9 * 12$ & 0.00 & $2 / 3 * 12$ & & & \\
\hline Fair, Men (Baseline) & 0.00 & 0.00 & -32.57 & -27.40 & -21.65 & -15.24 & -8.06 & 0.00 & 9.10 & $1.22(100.00)$ & $1.01(0.00)$ & $1.03(97.35)$ \\
\hline Fair, Women (Baseline) & 0.00 & 0.00 & -29.74 & -24.91 & -19.59 & -13.72 & -7.22 & 0.00 & 8.06 & $0.20(59.28)$ & $0.05(0.00)$ & $0.16(59.11)$ \\
\hline Fair, Men (Low Mortality) & 0.00 & 0.00 & -28.95 & -24.18 & -18.96 & -13.24 & -6.94 & 0.00 & 7.68 & $0.45(24.67)$ & $0.30(100.00)$ & $0.38(25.97)$ \\
\hline Fair, Women (Low Mortality) & 0.00 & 0.00 & -28.31 & -23.64 & -18.53 & -12.93 & -6.78 & 0.00 & 7.50 & $0.70(26.16)$ & $0.46(100.00)$ & $0.59(27.44)$ \\
\hline Exp. 4: $F R A \mathbf{6 9}, \mathbf{5 / 1 4}$ to $5 / 7$ & & & & & & & & & & & & \\
\hline Actual & -39.52 & -35.24 & -30.62 & -25.62 & -20.17 & -14.17 & -7.50 & 0.00 & 8.57 & & & \\
\hline (detail) & $-(5 / 14+\ldots+5 / 8) * 12$ & $-(5 / 13+\ldots+5 / 8) * 12$ & $-(5 / 12+\ldots+5 / 8) * 12$ & $-(5 / 11+\ldots+5 / 8) * 12$ & $-(5 / 10+\ldots+5 / 8) * 12$ & $-(5 / 9+5 / 8) * 12$ & $-5 / 8 * 12$ & 0.00 & $5 / 7 * 12$ & & & \\
\hline Fair, Men (Baseline) & -41.48 & -37.25 & -32.57 & -27.40 & -21.65 & -15.24 & -8.06 & 0.00 & 9.10 & $0.92(100.0)$ & $0.48(0.00)$ & $0.81(99.44)$ \\
\hline Fair, Women (Baseline) & -38.17 & -34.14 & -29.74 & -24.91 & -19.59 & -13.72 & -7.22 & 0.00 & 8.06 & $0.47(8.28)$ & $0.48(100.0)$ & $0.42(10.14)$ \\
\hline Fair, Men (Low Mortality) & -37.33 & -33.32 & -28.95 & -24.18 & -18.96 & -13.24 & -6.94 & 0.00 & 7.68 & $0.82(10.84)$ & $0.83(100.0)$ & $0.73(12.65)$ \\
\hline Fair, Women (Low Mortality) & -36.52 & -32.59 & -28.31 & -23.64 & -18.53 & -12.93 & -6.78 & 0.00 & 7.50 & $1.12(10.98)$ & $1.00(100.0)$ & $0.99(12.39)$ \\
\hline Exp. 5: $F R A \mathbf{6 9}, \mathbf{5 / 1 5}$ to $\mathbf{5 / 8}$ & & & & & & & & & & & & \\
\hline Actual & -36.02 & -32.02 & -27.74 & -23.12 & -18.12 & -12.67 & -6.67 & 0.00 & 7.50 & & & \\
\hline (detail) & $-(5 / 15+\ldots+5 / 9) * 12$ & $-(5 / 14+\ldots+5 / 9) * 12$ & $-(5 / 13+\ldots+5 / 9) * 12$ & $-(5 / 12+\ldots+5 / 9) * 12$ & $-(5 / 11+\ldots+5 / 9) * 12$ & $-(5 / 10+5 / 9) * 12$ & $-5 / 9 * 12$ & 0.00 & $5 / 8 * 12$ & & & \\
\hline Fair, Men (Baseline) & -36.02 & -32.02 & -27.74 & -23.12 & -18.12 & -12.67 & -6.67 & 0.00 & 7.50 & $2.37(100.0)$ & $1.47(0.00)$ & $2.08(99.22)$ \\
\hline Fair, Women (Baseline) & $\begin{array}{l}-38.17 \\
-38.17\end{array}$ & -34.14 & -29.74 & -24.91 & -19.59 & -13.72 & -7.22 & 0.00 & 8.06 & $0.92(100.0)$ & $0.52(0.00)$ & $0.81(99.36)$ \\
\hline Fair, Men (Low Mortality) & -37.33 & -33.32 & -28.95 & -24.18 & -18.96 & -13.24 & -6.94 & 0.00 & 7.68 & $0.55(100.0)$ & $0.16(0.00)$ & $0.48(99.82)$ \\
\hline Fair, Women (Low Mortality) & -36.52 & -32.59 & -28.31 & -23.64 & -18.53 & -12.93 & -6.78 & 0.00 & 7.50 & $0.24(100.0)$ & $0.00(0.00)$ & $0.21(100.0)$ \\
\hline
\end{tabular}

Notes: ${ }^{a} \mathrm{CV}$ (=Coefficient of Variation) measures the average relative deviation (in \%) between the present values of benefits before and/or after $F R A$ from their theoretically fair values. The percentage favorable measures the proportion of the total deviation for which the present value at an early or delayed take-up age exceeds the fair value. ${ }^{b}$ The "fair" numbers represent the percentage by which full benefits would have to be adjusted to be actuarially fair for a given take-up age. "Baseline" values refer to the baseline mortality scenario and "Low Mortality" values refer to the low mortality alternative scenario. 


\section{Table Appendix II. Multivariate Analysis of Actuarial Fit ${ }^{a}$, Cohorts 1917-1960}

\begin{tabular}{|c|c|c|c|c|c|c|}
\hline \multirow[b]{2}{*}{ Regressors } & \multicolumn{3}{|c|}{ Baseline (Constant Mortality) } & \multicolumn{3}{|c|}{ Low Mortality } \\
\hline & Model 1 & Model 2 & Model 3 & Model 1 & Model 2 & Model 3 \\
\hline Interest Rate & $\begin{array}{c}4.50^{* * *} \\
(1.22)\end{array}$ & $\begin{array}{c}4.50^{* * *} \\
(1.21)\end{array}$ & $\begin{array}{c}4.50^{* * *} \\
(1.22)\end{array}$ & $\begin{array}{c}4.50^{* * *} \\
(1.22)\end{array}$ & $\begin{array}{c}4.50^{* * *} \\
(1.21)\end{array}$ & $\begin{array}{c}4.50^{* * *} \\
(1.22)\end{array}$ \\
\hline Interest Rate Squared & $\begin{array}{c}116.31^{* * *} \\
(11.74)\end{array}$ & $\begin{array}{c}116.31^{* * * *} \\
(11.67)\end{array}$ & $\begin{array}{c}116.31^{* * *} \\
(11.74)\end{array}$ & $\begin{array}{c}116.31^{* * * *} \\
(11.75)\end{array}$ & $\begin{array}{c}116.31^{* * *} \\
(11.67)\end{array}$ & $\begin{array}{c}116.31^{\text {*** }} \\
(11.75)\end{array}$ \\
\hline Life Expectancy & $\begin{array}{c}-0.04^{* * *} \\
(0.01)\end{array}$ & $\begin{array}{c}-0.04^{* * *} \\
(0.01)\end{array}$ & $\begin{array}{c}-0.09^{* *} \\
(0.04)\end{array}$ & $\begin{array}{c}-0.05^{\text {*** }} \\
(0.01)\end{array}$ & $\begin{array}{c}-0.05^{* * *} \\
(0.01)\end{array}$ & $\begin{array}{l}-0.08 \\
(0.06)\end{array}$ \\
\hline Credit at Age 62 & $\begin{array}{c}0.07^{* * *} \\
(0.00)\end{array}$ & $\begin{array}{c}-14.46^{*} \\
(8.53)\end{array}$ & $\begin{array}{c}0.13^{* * *} \\
(0.05)\end{array}$ & $\begin{array}{c}0.06^{* * *} \\
(0.00)\end{array}$ & $\begin{array}{l}-12.62 \\
(8.53)\end{array}$ & $\begin{array}{l}0.12^{*} \\
(0.07)\end{array}$ \\
\hline Credit at Age 63 & & $\begin{array}{c}5.42 \\
(4.95)\end{array}$ & & & $\begin{array}{c}5.12 \\
(4.94)\end{array}$ & \\
\hline Credit at Age 64 & & $\begin{array}{c}5.84 \\
(5.55)\end{array}$ & & & $\begin{array}{c}4.80 \\
(5.55)\end{array}$ & \\
\hline Credit at Age 66 & & $\begin{array}{l}-6.68 \\
(6.19)\end{array}$ & & & $\begin{array}{l}-6.30 \\
(6.19)\end{array}$ & \\
\hline Credit at Age 67 & & $\begin{array}{c}8.42 \\
(8.32)\end{array}$ & & & $\begin{array}{c}7.84 \\
(8.32)\end{array}$ & \\
\hline Credit at Age 70 & $\begin{array}{c}-0.04^{* * *} \\
(0.00)\end{array}$ & $\begin{array}{l}-2.07 \\
(2.09)\end{array}$ & $\begin{array}{l}-0.02 \\
(0.02)\end{array}$ & $\begin{array}{c}-0.04^{* * *} \\
(0.00)\end{array}$ & $\begin{array}{l}-1.91 \\
(2.09)\end{array}$ & $\begin{array}{l}-0.01 \\
(0.02)\end{array}$ \\
\hline Credit 62 x Life Expectancy & & & $\begin{array}{c}0.00 \\
(0.00)\end{array}$ & & & $\begin{array}{c}0.00 \\
(0.00)\end{array}$ \\
\hline Credit 70 x Life Expectancy & & & $\begin{array}{c}0.00 \\
(0.00)\end{array}$ & & & $\begin{array}{c}0.00 \\
(0.00)\end{array}$ \\
\hline Constant Term & $\begin{array}{c}3.96^{* * *} \\
(0.12)\end{array}$ & $\begin{array}{l}-175.53 \\
(113.07)\end{array}$ & $\begin{array}{c}4.88^{* * *} \\
(0.91)\end{array}$ & $\begin{array}{c}3.79^{* * *} \\
(0.11)\end{array}$ & $\begin{array}{l}-149.56 \\
(113.09)\end{array}$ & $\begin{array}{c}4.51^{* * *} \\
(1.27)\end{array}$ \\
\hline R-Squared & 0.825 & 0.828 & 0.825 & 0.824 & 0.828 & 0.825 \\
\hline$\%$ Variation Explained by: & & & & & & \\
\hline Economic Variable $(s)$ & 55.64 & 55.55 & 55.62 & 55.67 & 55.45 & 55.65 \\
\hline Demographic Variable(s) & 5.23 & 3.41 & 2.84 & 10.44 & 5.93 & 5.74 \\
\hline Policy Variable(s) & 39.13 & 41.13 & 20.53 & 33.89 & 38.62 & 18.23 \\
\hline Interaction Terms & 0.00 & 0.00 & 21.01 & 0.00 & 0.00 & 20.39 \\
\hline
\end{tabular}

Notes: ${ }^{a}$ Dependent variable is the proximity to actuarial fairness (in logs) as measured by the CV (in \%).

*Statistically significant at the .10 level; ${ }^{* *}$ at the .05 level; ${ }^{* * *}$ at the .01 level. 


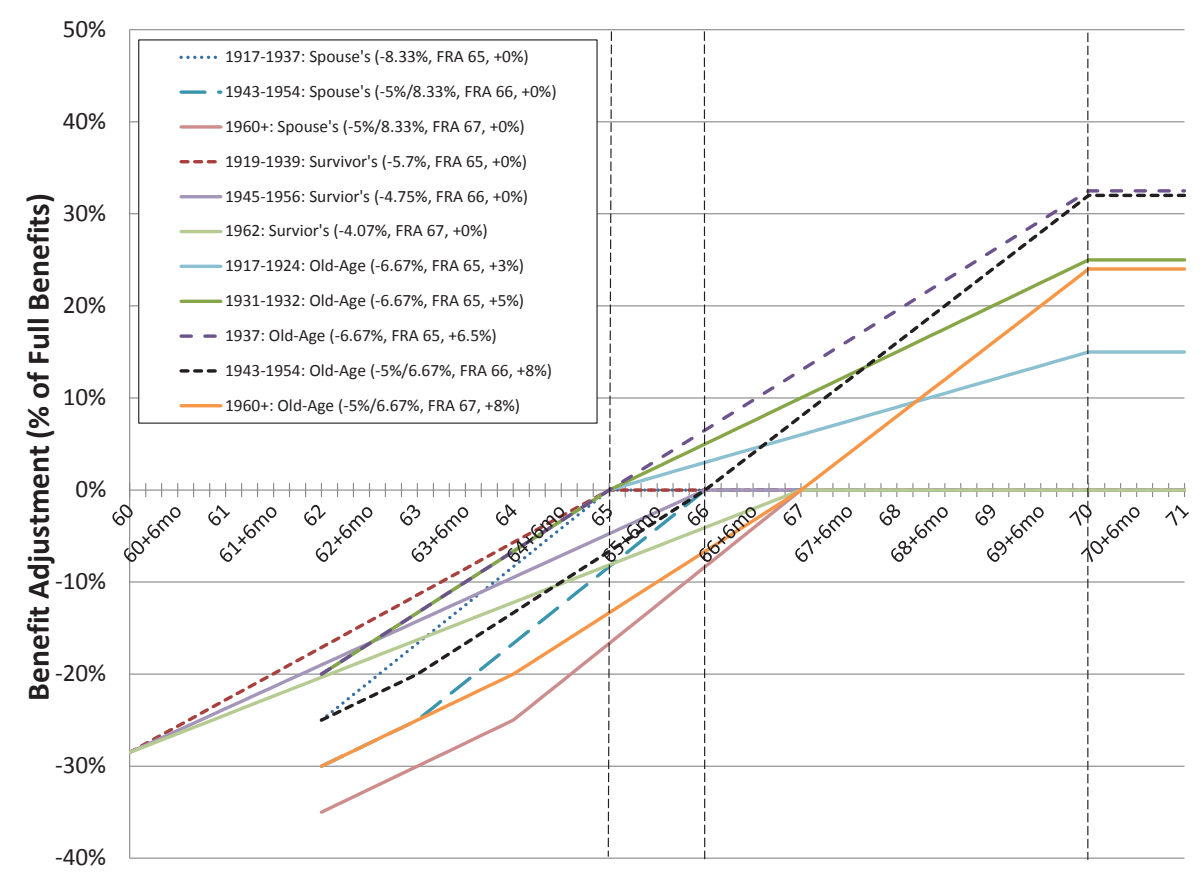

Age at Benefit Take up

Figure 1: Benefit Adjustment Schedules for Workers (Old-Age), Spouses, and Widow(er)s (Survivors), Selected Cohorts. (In parentheses: annual early and delayed adjustment percentages.)

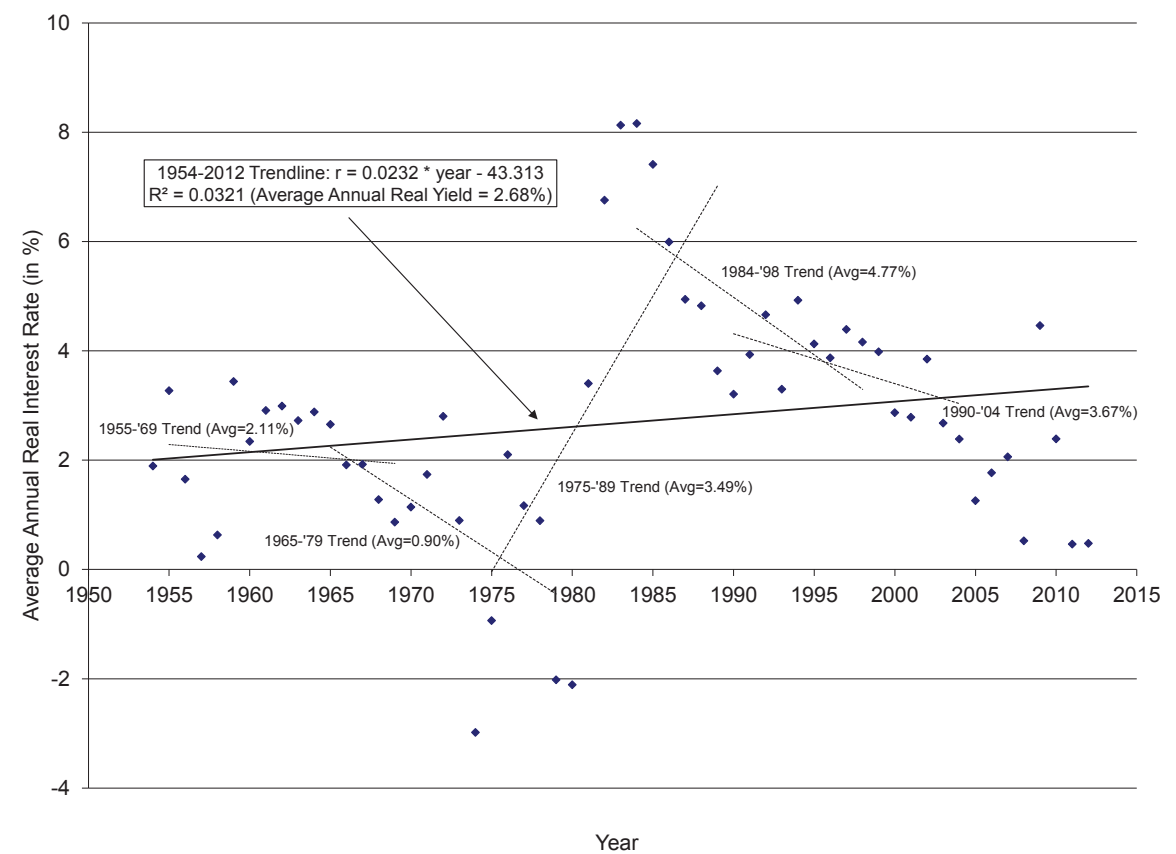

Figure 2: Average Annual Real Interest Rate of 20-year Constant Coupon Treasuries, Long-run and 15-year Linear Trends. 


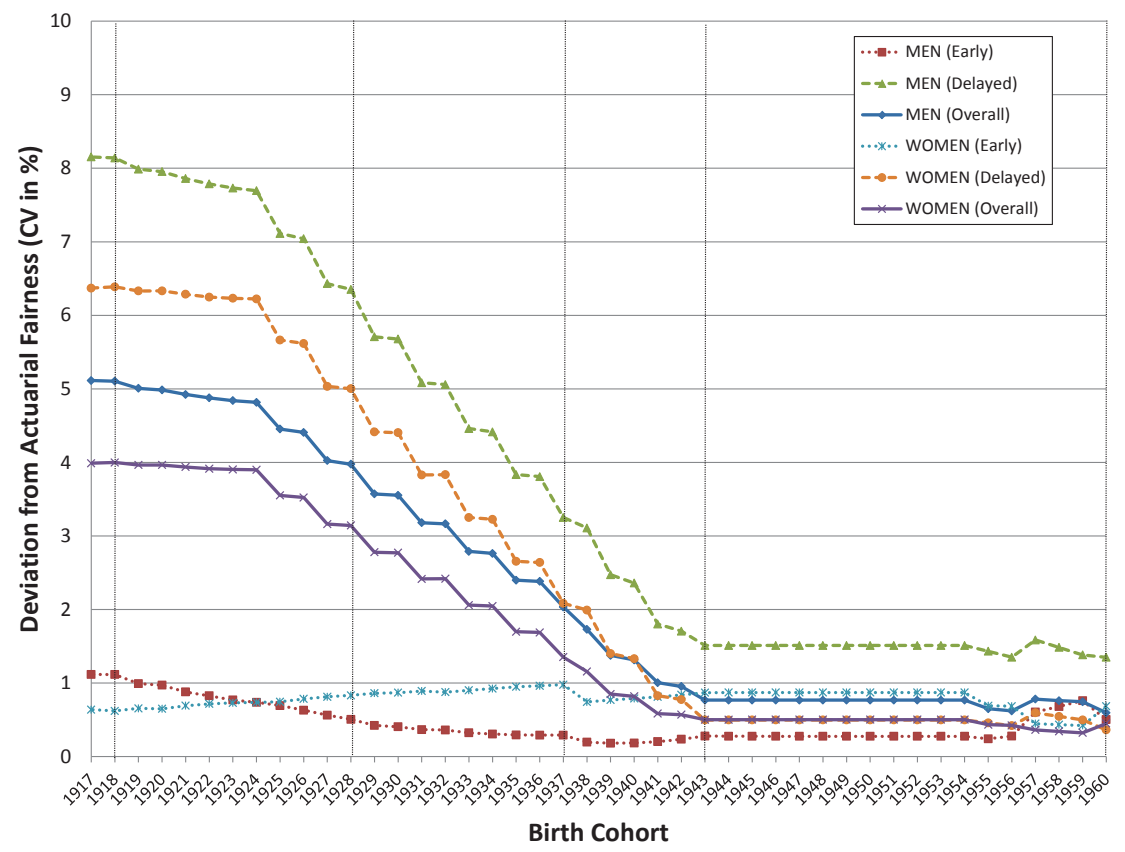

Figure 3: Deviation from Actuarial Fairness, Men and Women, 3\% Discount Rate, Baseline Mortality.

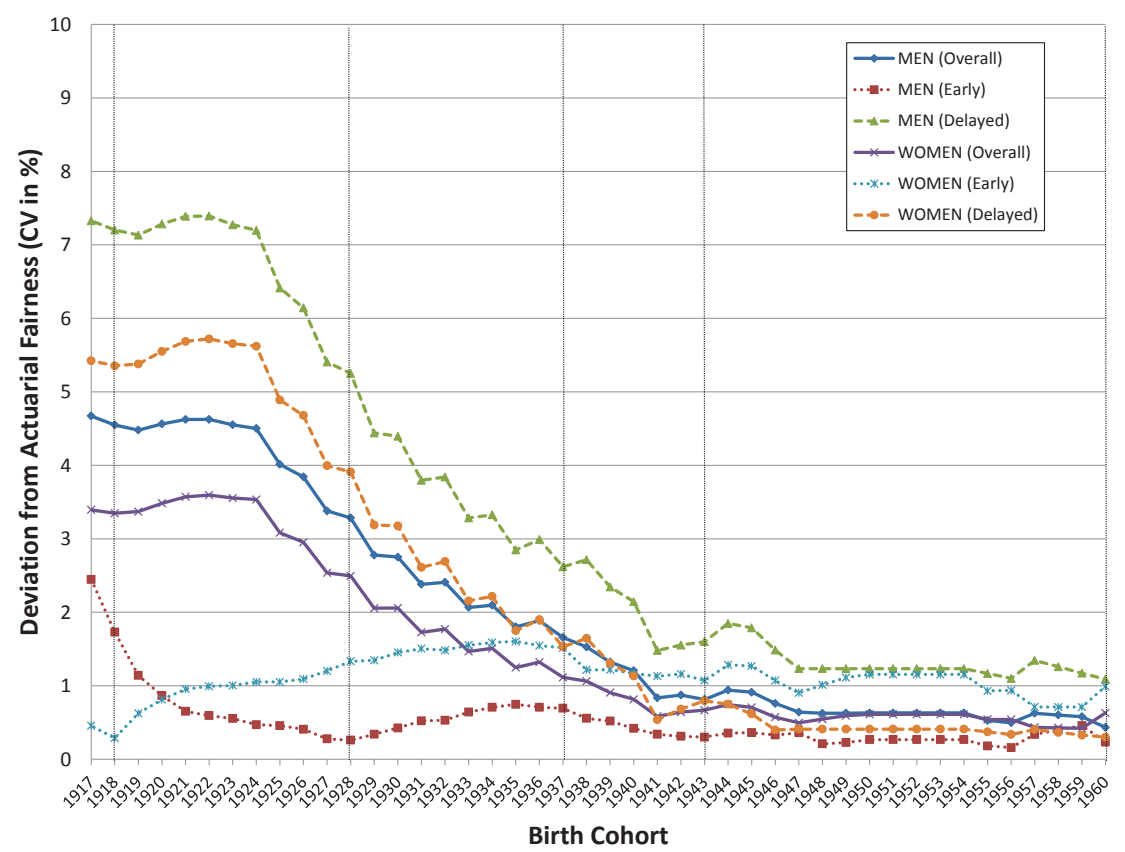

Figure 4: Deviation from Actuarial Fairness, Men and Women, Real Interest Rate Discounting, Baseline Mortality. 


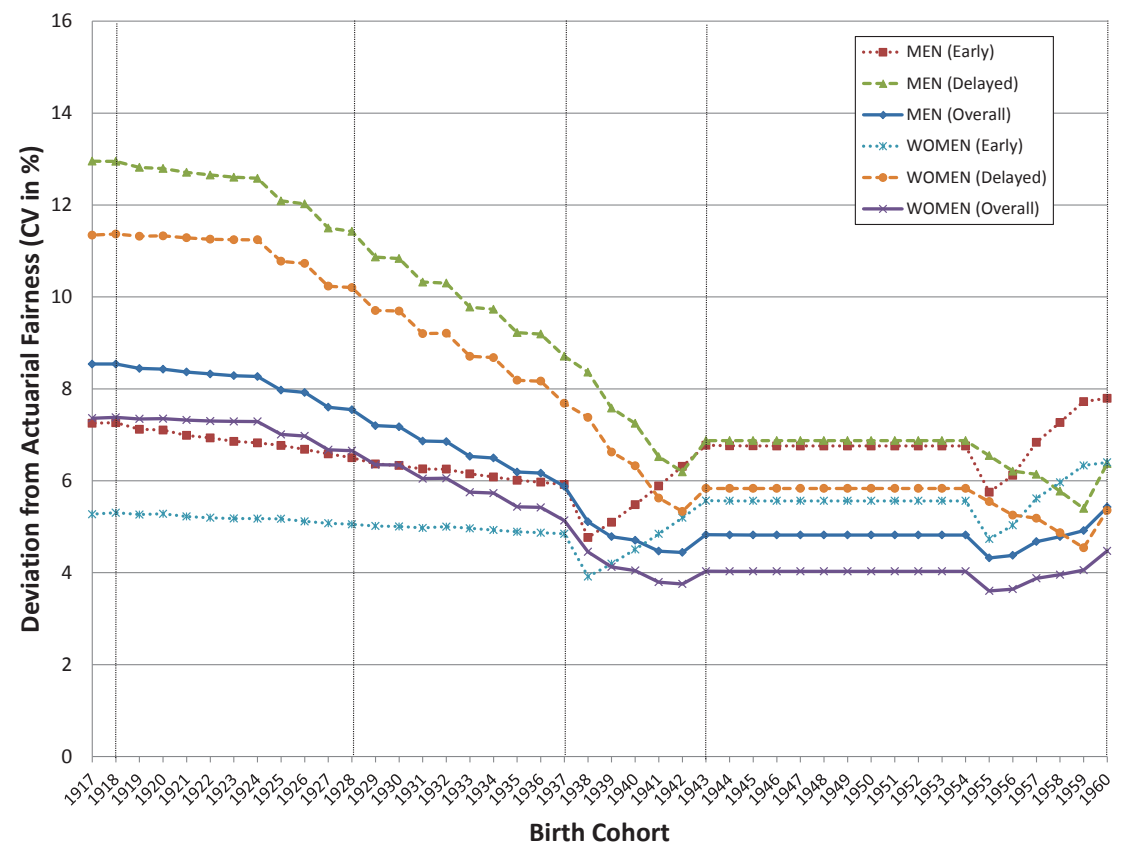

Figure 5: Deviation from Actuarial Fairness, Men and Women, 9\% Discount Rate, Baseline Mortality.

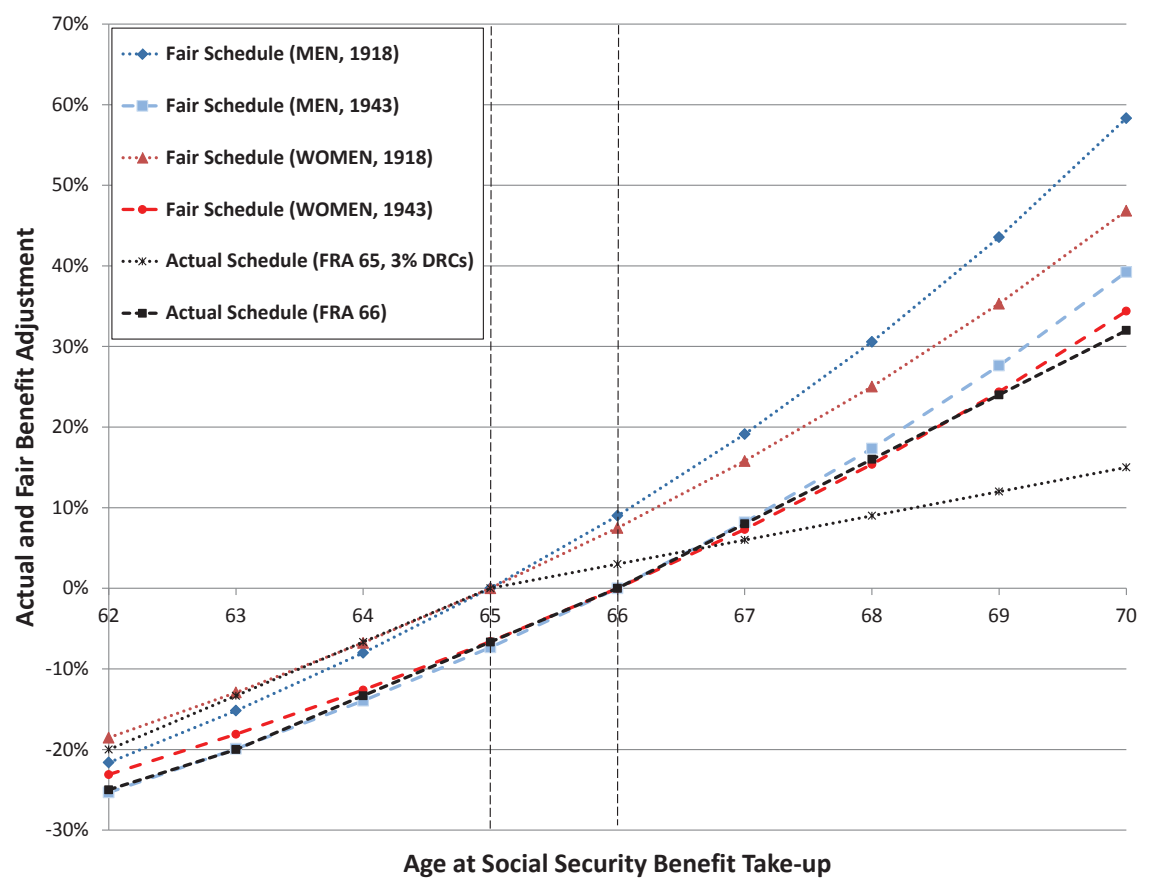

Figure 6: Actual and Actuarially Fair Adjustment Schedules, Men and Women, 1918 and 1943 Cohort, $3 \%$ Discount Rate, Baseline Mortality. 


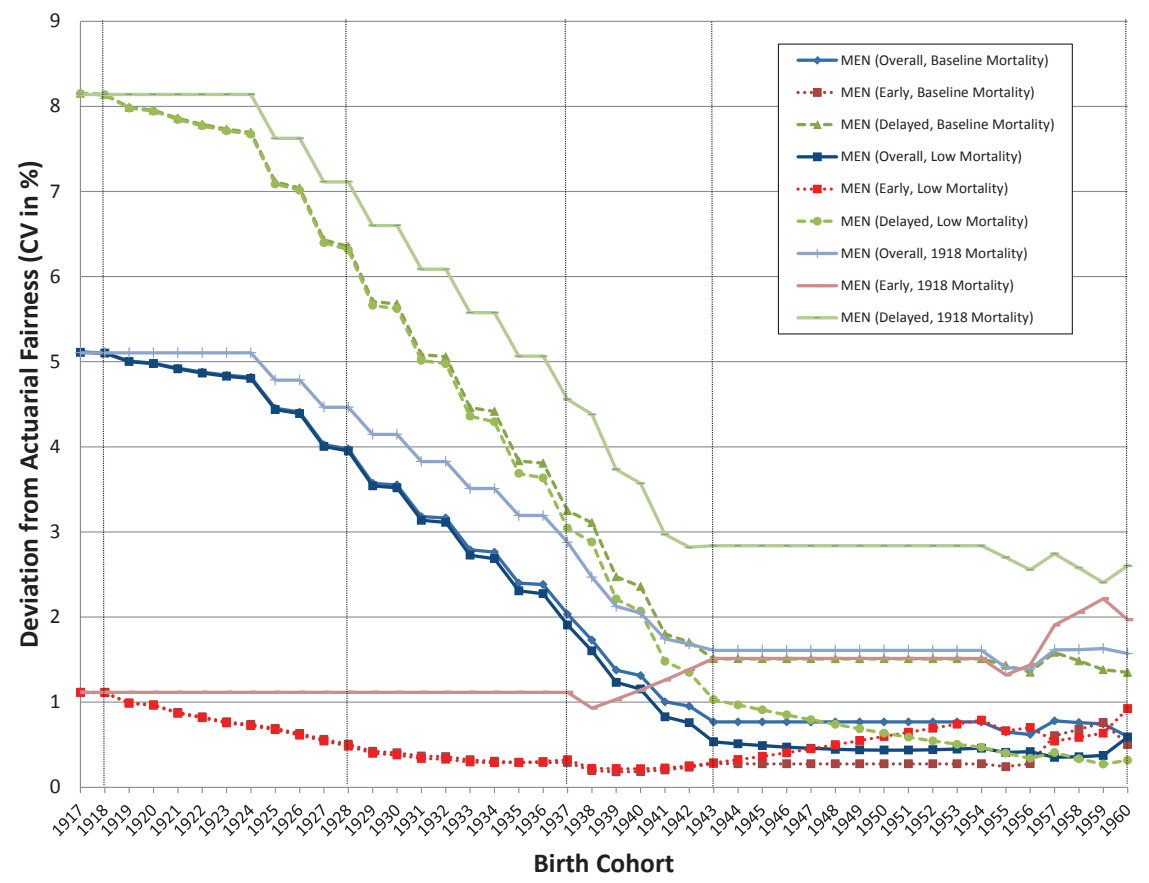

Figure 7: Deviation from Actuarial Fairness, Alternative Mortality Scenarios (Baseline, Low Mortality, 1918 Mortality), Men, 3\% Discount Rate.

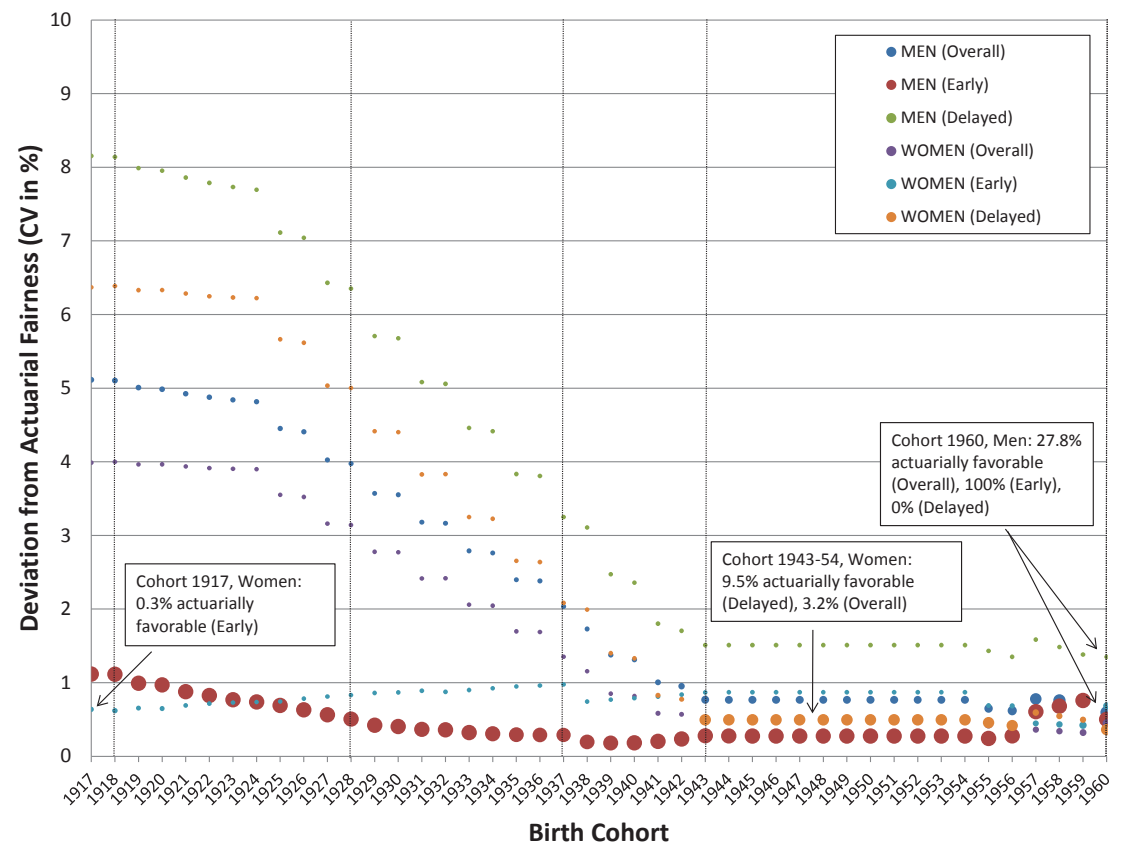

Figure 8: Actuarially Favorable Deviation for Claimers, Men and Women, 3\% Discount Rate, Baseline Mortality. 